\title{
VI. Sprachpolitik und Propaganda im Zeichen der militärischen und finanziellen Expansion (1939-1945)
}

Ausgelöst durch das Verbot der Parteikanzlei, Gelder in der Wirtschaft einzuwerben, kämpfte die Deutsche Akademie bei Kriegsausbruch einmal mehr um ihr finanzielles Überleben, obwohl sie nun mit Ministerpräsident Siebert einen „alten Kämpfer" an ihrer Spitze hatte. Der Kriegsausbruch schien in München, abgesehen von den finanziellen Schwierigkeiten, auch so interpretiert zu werden, daß die kulturpolitische Betätigung im Ausland vorerst zum Erliegen kommen werde. Das Goethe-Institut stellte seine Arbeit in München ein, und die für September anberaumte Jahresversammlung wurde kurzfristig abgesagt.

Es sollte jedoch ganz anders kommen. Auf der Sitzung des Kleinen Rates am 19. September 1939 erklärte von Twardowski, seit Mai Leiter der Kulturpolitischen Abteilung, im Namen von Staatssekretär Ernst von Weizsäcker, daß das Auswärtige Amt einer Liquidierung der Deutschen Akademie unmöglich zustimmen könne. Gerade in der gänzlich neuen Situation sei ihre Erhaltung eine dringende Notwendigkeit und dies um so mehr, als das Ausland angesichts der Schließung zahlreicher deutscher Universitäten mit Kriegsausbruch schon hämische Bemerkungen über den Kulturstand der Deutschen gemacht habe. Das Auswärtige Amt werde folglich alles tun, um den Fortbestand der Akademie zu sichern. Der Krieg werde nicht zuletzt durch das Ringen um die Seele der neutralen Länder entschieden; hier müsse die Kulturarbeit das leisten, was anderswo die Waffen bewerkstelligten. ${ }^{1}$

Zugleich gingen innerhalb der Akademie die Diskussionen weiter, wie man die Existenz der Einrichtung auf Dauer sichern könne. Generalsekretär FochlerHauke plädierte auf der Sitzung des Kleinen Rates am 12. Dezember 1939 dafür, die Akademie in eine öffentliche Einrichtung umzuwandeln, nicht zuletzt um den Mitarbeitern eine langfristige berufliche Perspektive zu bieten. Das bisher stets vorgebrachte Argument, die Akademie könne Kulturarbeit im Ausland überzeugender leisten, wenn sie den Schein der Unabhängigkeit durch ihren Charakter als privatrechtlicher Verein beibehalte, greife nicht mehr: Alle Entscheidungen seien ohnehin eng an die Direktiven des Auswärtigen Amts gebunden. Siebert hingegen hielt vorerst an der Idee fest, die Akademie als Verein weiterzuführen, der sich hauptsächlich auf Spenden der Wirtschaft stützen solle. Allerdings müsse das Auswärtige Amt seinen jährlichen Zuschuß auf 300000 bis 400000 RM erhöhen, um die Spracharbeit großzügig auszubauen. Auch der Vertreter des Auswärtigen Amts unterstrich, daß seine Behörde die Akademie weiterhin gerne als Verein mit Sitz in München sehen würde. ${ }^{2}$ 


\section{Intensivierung der Kulturpolitik mit Kriegsausbruch}

Von Twardowskis Ausführungen in München unmittelbar nach Kriegsausbruch machten deutlich, daß man in der Wilhelmstraße die kulturpolitische Lektion des Ersten Weltkrieges gelernt zu haben glaubte: Der Gefahr, daß das Reich wie ein Vierteljahrhundert zuvor auf der internationalen Bühne erneut als barbarische, aggressive Macht dargestellt werden könnte, wollten die Diplomaten durch eine ab Kriegsausbruch intensivierte Kulturpolitik im Ausland vorbeugen. Noch 1943 stellte von Twardowski in einer Aufzeichnung diesen eher defensiven, den Lehren des Ersten Weltkrieges geschuldeten Auftrag als die wichtigste Aufgabe der Kulturpolitischen Abteilung im Kriege heraus. Die Grundlegung der "geistigen Fundamente“ eines "neuen Europas“, also die ideologische Absicherung der deutschen Hegemonie über Europa, belegte in der Prioritätenliste erst die Ränge drei bis sieben der Aufstellung. ${ }^{3}$ Die sich seit September 1939 abzeichnende verstärkte Unterstützung der Deutschen Akademie durch das Auswärtige Amt war dabei nur ein Pfeiler der kulturpolitischen und propagandistischen Offensive, welche die Aggressionspolitik des Dritten Reiches verschleiern und zugleich unter der Hand unterstützen sollte. Vielmehr profitierten alle Aspekte der Arbeit der Kulturpolitischen Abteilung in materieller Hinsicht vom Kriegsausbruch: So gab es mehr Geld für den Ausbau des Auslandsschulwesens - die Schulfonds stiegen beispielsweise von 5,4 Millionen RM 1939 auf 13,3 Millionen RM 1941 - und mehr Stipendien für das Studium von Ausländern im Reich: 1936/37 hatte man 254 Ausländer gefördert, 1942/43 waren es 1650.4 Mit Kriegsausbruch ging das Auswärtige Amt, das sich Anfang September gegenüber seinem ewigen Konkurrenten, dem Propagandaministerium, zunächst bei Hitler die Federführung in der Auslandspropaganda hatte sichern können, ${ }^{5}$ ebenfalls daran, erstmals ein Netz zentral gesteuerter und einheitlich strukturierter Kulturinstitute im Ausland aufzubauen, die sogenannten Deutschen Wissenschaftlichen Institute (DWI). ${ }^{6} \mathrm{Sie}$ wurden in der Wilhelmstraße als wichtigster kulturpolitischer Beitrag zu den Kriegsanstrengungen des Reiches angesehen. ${ }^{7}$

3 PA Bd. R60804, Aufzeichnung über die Kulturpolitische Abteilung, 10. 4. 1943. Als ersten Punkt des Programms der Kulturpolitischen Abteilung im Kriege nannte das Dokument die Aufgabe, dem Ausland trotz des Krieges einen Eindruck vom kulturellen Selbstbehauptungswillen und den geistigen Reserven Deutschlands zu geben. An zweiter Stelle fand sich der Auftrag, der feindlichen Propaganda über die Kulturfeindlichkeit des Dritten Reiches entgegenzutreten.

4 Ebenda, Arbeitsprogramm der Kulturpolitischen Abteilung für 1942, 19.1. 1942 sowie Aufzeichnung über die Kulturpolitische Abteilung, 10. 4. 1943.

5 Peter Longerich, Propagandisten im Krieg. Die Presseabteilung des Auswärtigen Amtes unter Ribbentrop, München 1987, S. $135 \mathrm{f}$.

6 Vgl. zur Entstehung Michels, Das Deutsche Institut in Paris, S. 48-55 sowie Hausmann, „Auch im Krieg schweigen die Musen nicht“, S. 19-36.

7 So der ehemalige Leiter der Kulturpolitischen Abteilung, Franz Alfred Six, 1946 in einem Verhör durch die Amerikaner. In: IfZ Film 1300/3, Interrogation of F.A.Six, 30.4. 1946. Zu Six vgl. auch Lutz Hachtmeister, Der Gegnerforscher. Die Karriere des SS-Führers Franz Alfred Six, München 1998. 
Die Idee, repräsentative Kulturinstitute im Ausland zu errichten, kursierte im Auswärtigen Amt schon seit Mitte der dreißiger Jahre. Sie war u.a. angestoßen worden durch die Schenkung eines Deutsch-Amerikaners, der 1935 dem Reich ein repräsentatives Gebäude in Paris in der Avenue d'Iéna, heute Standort des Pariser Goethe-Instituts, mit der Auflage vermacht hatte, es zu einer deutsch-französischen Begegnungsstätte auszubauen. Als das Gebäude in Paris im Frühjahr 1938 eröffnet wurde, firmierte es als "Goethe-Haus" und diente vornehmlich als Residenz für deutsche Künstler. ${ }^{8}$ Auch im Hinblick auf London gab es, wie bereits erwähnt, seit 1937 Überlegungen, ein Kulturinstitut zu gründen. Allerdings wurden in Paris, London und anderen besonders wichtigen Hauptstädten die Aufgaben eines Kulturinstituts bis zum Kriegsausbruch in begrenztem Maße weiterhin von den Zweigstellen des DAAD wahrgenommen. ${ }^{9}$ Erst im Winter 1939/ 40, als die auswärtige Kulturpolitik den Stempel eines kriegswichtigen Beitrages an der geistigen Front erhielt, konnte die Kulturabteilung auch die nötigen Mittel vom Finanzministerium einfordern, um das Projekt „Kulturinstitute“ europaweit anzugehen.

Diesen Instituten, die sich in Zeiten des Krieges bewußt auch als wissenschaftliche Forschungseinrichtungen präsentieren sollten, um sich von bloßen Kulturinstituten wie den Instituts Français des Gegners abzusetzen, die angeblich lediglich „oberflächliche" Kulturpropaganda betrieben, ${ }^{10}$ stand daher stets ein renommierter deutscher Wissenschaftler und Kenner des Gastlandes vor. Er sollte für den wissenschaftlichen und daher vermeintlich unpolitischen Ruf des Instituts bürgen. Die Institute umfaßten als Kern neben einer gut bestückten, dem Publikum zugänglichen Bibliothek stets eine „wissenschaftliche Abteilung“, die eigenständige Forschungen betrieb. Ferner hatten sie eine "akademische Abteilung“, welche die Arbeit der ggf. früher im Lande vorhandenen Zweigstelle des DAAD übernahm. Schließlich erhielten sie auch jeweils eine Sprachabteilung, die stets die personell am stärksten besetzte war. Sie war identisch mit der jeweiligen Mittelstelle der Deutschen Akademie im Gastland. Die unter der Bezeichnung „Mittelstelle" seit Mitte der dreißiger Jahre arbeitenden Regionalbüros der Deutschen Akademie verloren also ihre Unabhängigkeit, indem sie zu Unterabteilungen der vom Auswärtigen Amt geschaffenen und beaufsichtigten neuen Kulturinstitute wurden. Das gleiche galt für die DAAD-Zweigstellen, die bislang wie die ganze Austauschorganisation dem RMEWV unterstanden hatten.

Die ersten Institute mit dieser einheitlichen Struktur, die im Auswärtigen Amt offenbar im Oktober oder November 1939 ausgearbeitet worden war, sollten nach Vorstellungen der Kulturpolitischen Abteilung auf dem Balkan eröffnet werden. ${ }^{11}$ Folglich nahm auch das Institut in Bukarest als erstes seine Arbeit im April

\footnotetext{
8 Twardowski, Anfänge deutscher Kulturpolitik zum Ausland, S. 41.

9 Laitenberger, Akademischer Austausch und auswärtige Kulturpolitik, S. 71 f. und $115 \mathrm{ff}$.

10 Barbian, Kulturwerte im Zweikampf, S. 430 Anmerkung 61.

11 BAB R51/51, Aufzeichnung Twardowskis betr. Kulturinstitute auf dem Balkan, 18. 11. 1939. In dieser Aufzeichnung findet sich bereits die grundsätzliche, später für die DWI maßgebliche Unterteilung in eine wissenschaftliche, eine akademische und eine Sprachabteilung.
} 
1940 auf. Die Institute ergänzten ebenso wie die auf dem Balkan nun noch verstärkte Tätigkeit der Deutschen Akademie kulturpolitisch die bis Kriegsausbruch schon weit fortgeschrittene ökonomische Unterwanderung Südosteuropas durch das Reich. Denn man rechnete in Berlin mit einer intensivierten kulturpolitischen Offensive der Gegner in dem vorerst neutralen, für Deutschland aber ökonomisch wie strategisch immens wichtigen Großraum. Da die Balkanstaaten nach den Vorstellungen Berlins vorerst möglichst neutral bleiben sollten, weil so die möglichst ungestörte Nutzung ihrer wirtschaftlichen Ressourcen für das Reich am besten gewährleistet war, ${ }^{12}$ erschien eine verstärkte kulturpolitische Präsenz ein geeignetes Mittel, hier in Kriegszeiten Flagge zu zeigen, ohne die Intervention anderer Mächte heraufzubeschwören.

Als erste Stützungsmaßnahme des Auswärtigen Amts erhielt die Deutsche Akademie Anfang Januar 1940 einen Sonderzuschuß von 100000 RM für die Spracharbeit, der insbesondere für die Ausstattung der bestehenden Lektorate in Südosteuropa verwendet werden sollte. Weitere Gelder stellte die Wilhelmstraße in den nächsten Monaten bereit. Ende Juni 1940 informierte München beispielsweise die Lektorate, daß demnächst Radios, Schreibmaschinen, Stapeldrucker, Lichtbildgeräte, Farblichtdrucke und Stiche an sie versandt würden. Zudem bestehe nun die Möglichkeit, ausländischen Kursteilnehmern akademischer Berufe wie Ärzten, Chemikern und Ingenieuren für einige Zeit kostenlos Abonnements deutscher Fachzeitschriften zukommen zu lassen. Ab 1. Juli würden den Lektoraten auch "namhafte“ Mittel zur Abhaltung "geselliger" Veranstaltungen wie z.B. Teenachmittagen und Abendeinladungen zur Verfügung stehen. ${ }^{13}$ Allerdings sollten diese Veranstaltungen nicht zu "gesellig“ geraten: Als einige Jahre später ein Mittelstellenleiter anfragte, ob in den Lektoraten auch Tanzveranstaltungen erlaubt seien, machte der Leiter der Abteilung Auslandslektorate, Nitschke, dies von einer Genehmigung der jeweiligen diplomatischen Mission abhängig. Er fügte aber hinzu: „Wir persönlich stehen auf dem Standpunkt, daß nicht getanzt werden sollte". 14

Spracharbeit biete, so die Begründung des Auswärtigen Amts im Frühjahr 1940 gegenüber dem Reichsfinanzministerium beim Antrag auf zusätzliche Gelder für die Deutsche Akademie, in Kriegszeiten eine unverdächtige Art der Beeinflussung des neutralen Auslandes, das auf politische Propaganda ablehnend reagiere. Ziel der Sprachwerbung sei es nicht, den Ausländern mehr oder weniger Deutsch beizubringen oder im Rahmen des Unterrichts Propagandaschriften in ihrer Muttersprache in die Hand zu drücken. Derartige Versuche hätten stets mehr Schaden als Nutzen eingebracht. Der Sprachunterricht bewirke vielmehr, daß „der Ausländer von da ab Deutschland nicht mehr gleichgültig gegenübersteht und unwillkürlich und fast automatisch sich über deutsche Dinge zu unterrichten suchen wird und allmählich ein wirkliches Interesse an Deutschland und seiner Ideenwelt

12 Vgl. Klaus Olshausen, Dic deutsche Balkanpolitik 1940/41, in: Hitler, Deutschland und die Mächte, hrsg. von Manfred Funke, Düsseldorf 1976, S. 707-727.

13 BAB R51/23, Rundschreiben an die Lektorate, 27.6. 1940.

14 BAB R51/26, Protokoll der Tagung der Mittelstellenleiter, 11.-16. 2. 1944. 
nimmt “. ${ }^{15}$ Selbst nach Kriegsausbruch hielt man also in der Kulturpolitischen Abteilung zumindest theoretisch an der Trennung von Kulturpolitik und Propaganda fest. Für die mehr auf die Tagespolitik ausgerichtete Beeinflussung des Auslandes hatte man im übrigen im Sommer 1939 eine "Informationsabteilung“ im Auswärtigen Amt eingerichtet, die, obwohl Propaganda betreibend, dennoch den odiösen Begriff mied. Die Abgrenzung gegenüber kruden Propagandamethoden bestand allerdings eher in der Theorie denn in der Praxis: Allein zwischen Herbst 1939 und Frühjahr 1940 vertrieben die Lektorate der Deutschen Akademie, deren Arbeit weiterhin vom Referat Sprache innerhalb der Kulturpolitischen Abteilung betreut wurde, in Bulgarien mehrere tausend Exemplare der Druckschrift „Polnische Greueltaten“, bis das Auswärtige Amt selbst den Versand weiterer Exemplare stoppte, da man um den Ruf der Lektorate fürchtete. Anfang 1940 wurde zudem ein Lektor der Akademie von der jugoslawischen Polizei verhaftet, da die deutsche Gesandtschaft in Belgrad ihm paketeweise Propagandamaterial zugesandt hatte. ${ }^{16}$

Daß Kriegszeiten einer unpolitischen, sich von bloßer Propaganda absetzenden Kulturarbeit nicht dienlich waren, sah man im übrigen 1940 auch beim British Council. „It is not possible to distinguish the borderline between cultural and political propaganda in wartime", schrieb sein Vorsitzender Lord George Lloyd im November 1940. Dennoch wurde nach außen hin auch in London an der Fiktion einer Trennung von Propaganda und Kulturpolitik festgehalten, da andernfalls die Gefahr bestand, daß der British Council aus der Obhut des Foreign Office gelöst und dem mit Kriegsausbruch geschaffenen Ministry of Information unterstellt worden wäre. Dies wäre nicht nur für das Ansehen und die Wirksamkeit der Arbeit des British Council fatal gewesen, sondern hätte auch für die nicht einmal fünf Jahre alte Organisation die Gefahr heraufbeschworen, ebenso wie das britische Informationsministerium, das wie im Ersten Weltkrieg eine rein kriegsbedingte Einrichtung sein sollte, bei Friedenschluß schlichtweg wieder aufgelöst zu werden. ${ }^{17}$ So machte sich denn Lord Lloyd die gleichen Argumente zu eigen, mit denen die Kulturpolitische Abteilung des Auswärtigen Amts in Berlin auf die angeblich größere Effizienz von kulturellen Initiativen gegenüber plumper politischer Propaganda hinwies, um nicht dem Ministry of Information unterstellt zu werden: "It is a fundamental paradox that the political effect of cultural propaganda increases in proportion to its detachment from political propaganda, no matter how honestly and candidly the latter may be conducted and however wide the evidence it may win." 18

Das Auswärtige Amt zahlte bis Jahresende 1940 insgesamt $860000 \mathrm{RM}$ an die Deutsche Akademie, also mehr als das Zehnfache der Summe, welche 1938/39 für den Münchener Verein zur Verfügung gestanden hatte. Dies war aber erst der Anfang, denn 1941 erübrigte das Amt sogar 3,3 Millionen RM, so daß der Gesamtetat

15 BAB R2/11497, Aufzeichnung der kulturpolitischen Abteilung über die notwendige Etaterhöhung für die Spracharbeit, Frühjahr 1940.

16 Scholten, Sprachverbreitungspolitik des nationalsozialistischen Deutschlands, S. 411.

17 Donaldson, The British Council, S. $70 \mathrm{f}$.

18 Ebenda, S. 74. 
der Akademie inklusive Spenden aus der Wirtschaft und Eigeneinnahmen aus den Sprachkursen auf 4,4 Millionen RM anwuchs. ${ }^{19}$ Auch im Vereinigten Königreich stiegen im übrigen die Ausgaben für auswärtige Kulturpolitik seit Kriegsausbruch kontinuierlich, wenn auch anfänglich nicht so drastisch wie die Zuschüsse für die Deutsche Akademie. Betrug der letzte Friedenshaushalt des British Council für 1939/40 immerhin schon 330000 Pfund, so war er im Rechnungsjahr 1941/42 auf 611728 Pfund angewachsen. 1944/45 verfügte die britische Organisation schließlich über 2,1 Millionen Pfund.20

Anfang 1941 zählte die Akademie bereits 120 Lektoren im Ausland, zudem hatte man 52 Hilfslehrkräfte vor Ort engagiert. Die Zahl der Sprachschüler war von etwa 7000 bei Kriegsausbruch auf nunmehr 17000 angewachsen. ${ }^{21}$ Vor allem aber war nun die materielle Ausstattung der Lektorate verbessert worden. Allein schon vom äußeren Erscheinungsbild her hatte man sich bislang gegenüber der französischen, italienischen und britischen Konkurrenz benachteiligt gefühlt und war daher vor dem Krieg gerne in Provinzstädte ausgewichen, in denen es gar keine anderen ausländischen Kulturstützpunkte gab. Nun hingegen brachte man die Lektorate in ansprechenden, zentral gelegenen Gebäuden unter, zumindest in Italien nach Aussage Wüsts oftmals sogar in „palastartigen Häusern“.22 Ferner bekamen sie alle kleine Bibliotheken von, je nach Größe des Lektorates, ${ }^{23} 1000$ bis 3000 Bänden, ebenso Schallplattenspieler und Schallplatten, Diaprojektoren, Radiogeräte, Bilderschmuck, Landkarten etc. Sie wurden jetzt regelmäßig mit den wichtigsten Zeitungen und Zeitschriften aus Deutschland beschickt, vom „Völkischen Beobachter" über „Das Reich" bis zur "Leipziger Illustrierten Zeitung". Die Lektorate erhielten nun ein einheitliches Mobiliar, das von einem eigens dafür engagierten Innenarchitekten entworfen worden war und "gediegene deutsche Wohnkultur" ausstrahlen sollte. ${ }^{24} \mathrm{Ab} 1941$ gehörte zur Ausstattung auch jeweils eine „Führerbüste“.

„Damit die Arbeit der Deutschen Akademie der Würde des Großdeutschen Reiches entspricht, habe ich veranlaßt, daß auch in den räumlichen Verhältnissen das jeweilige Auslandslektorat der Deutschen Akademie entsprechende Formen gewinnt. Es ist beabsichtigt, eine jede derartige Vertretung der Deutschen Akademie auch im Äußeren so würdig ausstatten zu lassen, daß die Ausländer, die es besuchen, dadurch einen unmittelbar wirksamen Begriff vom deutschen Lebensstil gewinnen und sich dessen bewußt werden, daß sie sich im geistigen Raum eines Volkes bewegen, das berufen ist, Europa ein neues Gesicht zu geben“,

schrieb Siebert. 25

Jedes Lektorat konnte ab 1941 jährlich zwei Stipendien für Sommerkurse am Goethe-Institut in München an besonders gute Sprachschüler oder Deutschlehrer

19 Zahlen in: BAB R2/11622.

20 Donaldson, The British Council, S. 382.

21 Zahlen in: BAB R51/10149 (Personal) und BAB R51/35 (Hörer).

22 Wüst, Gedenkrede für den verstorbenen Präsidenten der Deutschen Akademie, S. 360.

23 Die Zahl der Lektoren pro Lektorat variierte von beispielsweise 20 in Paris tätigen Kräften bis zu Einmann-Lektoraten wie z. B. in Alicante, Dubrovnik oder Göteborg.

24 Walter Kunze, Die Spracharbeit der Deutschen Akademie, in: Jahrbuch der Deutschen Sprache, 2 (1944), S. 135-142, hier S. 137.

25 Völkischer Beobachter, 19. 10. 1940, S. 1. 
vergeben. Dieses nahm im Sommer 1941 seine Arbeit wieder in vollem Umfang auf, nachdem es ein neues Haus in der Maria-Josepha-Straße in München bezogen hatte. Die Sommerkurse in München zogen in den Kriegsjahren jährlich zwischen 300 und 500 Sprachschüler an, zumeist, aber nicht ausschließlich, Stipendiaten der Auslandslektorate. Daneben hatten die Lektorate die Möglichkeit, Buchgeschenke an besonders gute Sprachschüler zu verteilen, ein Idee, die schon in den dreißiger Jahren von Thierfelder initiiert worden war, nun aber erst mit der verbesserten finanziellen Situation der Akademie großzügig gehandhabt werden konnte. Allein zwischen Frühjahr 1942 und Frühjahr 1943 wurden 200000 RM nur für den Versand von Büchern an die Lektorate ausgegeben, also etwa das Dreifache dessen, was die Deutsche Akademie für ihre gesamte Spracharbeit in den dreißiger Jahren als Reichszuschuß erhalten hatte.

Für 1942 forderte das Auswärtige Amt trotz der bereits seit Kriegsausbruch erreichten Etatsteigerung noch mehr Geld für die Deutsche Akademie:

„Die Erhöhung des Etats der Deutschen Akademie ist auf die politische Entwicklung zurückzuführen, die im Verlauf der vergangenen 11/4 Jahre das Bild der sich für die deutsche Sprachpolitik ergebenden Möglichkeiten und Bedürfnisse von Grund auf verändert hat. Abgesehen davon, daß ein im hohen Grade gesteigertes Bedürfnis nach der Erlernung der deutschen Sprache in den verschiedenen Ländern zu verzeichnen war, ergab sich auch die Notwendigkeit für unsere Sprachenpolitik, in die von den Feindstaaten teilweise geräumten Positionen so schnell wie möglich einzudringen",

hieß es in der Etatbegründung der Kulturpolitischen Abteilung im August 1941, in der sie die benötigten Mittel für das kommende Jahr für die Münchener Einrichtung auf 5,5 Millionen RM veranschlagte. ${ }^{26}$ Auch diese Summe wurde bewilligt, wie überhaupt ab 1940 für die Deutsche Akademie Geldmangel nie mehr ein Problem sein sollte. Bei einem seit Kriegsausbruch ständig an Umfang zunehmenden Reichshaushalt - von 50 Milliarden Reichsmark im letzten Friedenshaushalt auf etwa 90 Milliarden im ersten, 148 Milliarden im zweiten und 218 Milliarden RM im dritten Kriegsjahr - war stets genügend Geld vorhanden für alle Forderungen, die den Stempel der Kriegswichtigkeit erhielten. Die Ausgabenpolitik des Reiches richtete sich nun nicht mehr nach den zu erwartenden Einnahmen. Diese wurden vielmehr durch ungezügelte Kreditaufnahme und zu einem kleineren Teil durch Steuererhöhungen und Ausplünderung der besetzten Länder den finanziellen Forderungen der Reichsressorts angepaßt. ${ }^{27}$ Zudem fiel für die kulturpolitische Betätigung in einem Großteil Europas seit 1940 die Notwendigkeit weg, wertvolle Devisen bereitzustellen, während die Devisenbewirtschaftung im Rahmen des Vierjahresplanes bis 1939 das Haupthindernis eines großzügigen Ausbaus der Spracharbeit durch das Auswärtige Amt gewesen war. Den besetzten Ländern konnte nun ein beliebiger Wechselkurs oktroyiert werden - im Falle Frankreichs beispielsweise war eine RM seit 1940 mit 20 Francs zu verrechnen oder man konnte die Kulturarbeit indirekt durch die von den eroberten Ländern

26 BAB R2/11629, Haushaltsansatz für die deutsche Sprachwerbung im Ausland, 29. 8. 1941. 27 Vgl. dazu überblicksartig Willi A. Boelcke, Die Finanzpolitik des Dritten Reiches. Eine Darstellung in Grundzügen., in: Deutschland 1933-1945. Neue Studien zum NS-Herrschaftssystem, hrsg. von Karl-Dietrich Bracher u.a., Düsseldorf 1992, S. 95-117. 
aufzubringenden Besatzungskosten finanzieren. Der Geldsegen, der in den Kriegsjahren aus den Kassen des Reiches über die Deutsche Akademie kam, führte, wie eine nachträgliche Überprüfung ihrer Bücher durch den Bayerischen Landesrechnungshof Ende Mai 1946 ergab, zur regelrechten Verschwendung öffentlicher Gelder: Die Besoldung der Mitarbeiter war teilweise sehr großzügig bemessen worden und die Ausgaben für Telefonkosten und Dienstreisen waren selbst im letzten Kriegsjahr noch unverhältnismäßig hoch. ${ }^{28}$

Der mit Kriegsausbruch forcierte Ausbau des Lektoratsnetzes der Deutschen Akademie hatte mehrere Gründe. Zunächst wurde im Auswärtigen Amt wie auch in der Deutschen Akademie der Krieg als eine Chance gesehen, der Sprachwerbung endlich durch den Stempel der Kriegswichtigkeit die nötigen Mittel zukommen zu lassen, die zuvor vom Reichsfinanzministerium blockiert worden waren. War die Kulturpolitik 1939/40 noch eher defensiv ausgerichtet, d.h. vornehmlich dadurch motiviert, nicht die gleichen Fehler wie im Ersten Weltkrieg zu begehen und dem Gegner das Feld der Beeinflussung der Öffentlichkeit in den neutralen Ländern zu überlassen, so nahmen die Zukunftspläne nach dem überraschend schnellen Sieg über Frankreich ganz andere Dimensionen an. Den nun überall in den deutschen Ministerien und Dienststellen einsetzenden, teilweise phantastisch anmutenden Neuordnungsplänen für ein Europa unter deutschem Vorzeichen, aber auch für ein zu errichtendes überseeisches Imperium, ${ }^{29}$ fanden Unterstützung in der Kulturpolitischen Abteilung und der Deutschen Akademie. Nun galt es, Deutschland zu einer Großmacht auszubauen, die einen auch kulturellen Führungsanspruch in Europa nicht nur erhob, sondern auch durchsetzte. Seit Sommer 1940 wurde ganz unverhohlen in der Akademie wie im Auswärtigen Amt darauf hingearbeitet, die deutsche Sprache zur dominierenden Sprache in Europa zu machen.

Siebert stimmte in den Chor derer ein, die hybride Neuordnungsvorschläge für ein Europa unter deutscher Herrschaft machten. So schrieb er im Oktober 1940 an die Reichskanzlei, er wolle mittels der Deutschen Akademie nun Deutsch zur wichtigsten Weltsprache ausbauen, ein Vorhaben, das auch vom Propagandaministerium unterstützt werde. Daher bitte er auch um einen Finanzzuschuß aus den Fonds des „Führers“, u.a. um der Akademie endlich ein repräsentatives Gebäude in München bauen zu können. ${ }^{30}$ Er hielt mit den sprachpolitischen Zielen der Akademie auch in der Öffentlichkeit nicht hinter dem Berg: Auf Seite eins der Ausgabe des „Völkischen Beobachters“ vom 19. Oktober 1940 prangte ein von ihm verfaßter Artikel mit der Überschrift „Deutsch als Weltsprache - Auftrag an die Deutsche Akademie“, in dem es u.a. hieß:

28 BHStA MK Registratur-Spalte V/1274, Bericht über den Stand der Abwicklung der aufgelösten Deutschen Akademie, Mai 1946.

29 Beispiele liefert Ralf Giordano, Wenn Hitler den Krieg gewonnen hätte. Die Pläne der Nazis nach dem Endsieg, Hamburg 1989, passim. Zu den kolonialpolitischen Planungen vgl. Klaus Hildebrand, Vom Reich zum Weltreich. Hitler, NSDAP und koloniale Frage 19191945 , München 1969, S. 900 ff.

30 BAB R43/II/1230a, Schreiben Sieberts an die Reichskanzlei, 3. 10. 1940. 
„Das Deutsche hat bereits viele Gebiete für sich gewinnen können. Es wird nach den Siegen, die unsere Waffen errungen haben und noch erringen werden, seinen Einfluß noch in einem Maße zu steigern wissen, wie es die meisten unter uns im Augenblick kaum ermessen können [...] Das deutsche Volk wird durch sein Geistesgut und durch seine Lebensart ebensosehr die Augen der Welt auf sich lenken wie durch den Sieg seiner Waffen. Darum genügt es nicht mehr, daß sich der Mitarbeiterstab der Auslandslektorate der Deutschen Akademie mit den gegenwärtigen Zahlen begnügt. Es wurde daher beschlossen, mit sofortiger Wirkung den Mitarbeiterstab der Auslandslektorate erheblich zu erhöhen, damit die Deutsche Akademie alle Ansprüche, die bereits an sie gestellt werden, in einer der Größe des Deutschen Reiches entsprechenden Weise erfüllen kann.“

Interessanterweise berief sich Siebert in diesem Artikel nicht etwa auf einen „Führerbefehl“ oder eine Weisung des Auswärtigen Amts oder einer sonstigen Stelle. Vielmehr scheinen Siebert und seine Mitarbeiter in der Akademie sich den Auftrag „Weltsprache Deutsch“ aus eigenem Antrieb gestellt zu haben. Es war ein klassisches Beispiel dafür, daß es in der Euphorie des Sieges im Dritten Reich keines „Führer-“" oder sonstigen Befehls bedurfte, um auch in untergeordneten Instanzen die größenwahnsinnigsten Projekte zu konzipieren oder die radikalsten Lösungen anzustreben. Auch in der Deutschen Akademie „arbeitete man dem Führer entgegen "31, indem man seine angeblichen Wünsche und Visionen antizipierte. In einer Aufzeichnung der Kulturpolitischen Abteilung vom Dezember 1940 hieß es entsprechend über zukünftig abzuschließende Kulturverträge mit europäischen Staaten, diese seien so abzufassen, daß der deutschen Sprache die Stellung als vorherrschende Vermittlungssprache gesichert werde. ${ }^{32}$ Ausgehend von dieser Zielsetzung waren die mit Bulgarien im Juni 1940 und der Slowakei im Mai 1942 unterzeichneten Kulturverträge so konzipiert, daß die Vertragspartner der deutschen Sprache eine privilegierte Stellung als erste Fremdsprache einräumen mußten. Im Falle des im November 1941 mit Rumänien abgeschlossenen Kulturvertrages konnte sich Bukarest unter Hinweis auf die traditionell starke Stellung des Französischen im Lande immerhin gegen eine entsprechende Klausel wehren und verpflichtete sich lediglich, der deutschen Sprache an den Schulen und Hochschulen das Gewicht einzuräumen, das ihr gemäß der besonderen Bedeutung der deutschen Sprache im politischen und wirtschaftlichen Leben Rumäniens zukomme. Dies wäre allerdings angesichts der Einbindung Rumäniens in den deutschen Machtbereich auf eine Vorrangstellung der deutschen Sprache hinausgelaufen. ${ }^{33}$

Der seit Anfang 1940 einsetzende Geldsegen aus den Kassen des Auswärtigen Amts hatte seinen Preis: Die Deutsche Akademie mußte hinnehmen, daß ihre Lektorate seit Sommer 1940 zu bloßen Sprachabteilungen der neugegründeten Deutschen Wissenschaftlichen Institute degradiert wurden. Diese bestimmten nunmehr zusammen mit den Diplomaten in Berlin über die Einrichtung und Dislozierung neuer Lektorate sowie das über die Sprachkurse hinausgehende Kulturprogramm, also z. B. darüber, welche Vortragsredner aus dem Reich die Lektorate einladen durften. Selbst die Bezeichnung „Lektorat der Deutschen Akademie“

31 Vgl. hierzu Ian Kershaw, Hitler. Hubris 1889-1936, London 1999, S. 529-531.

32 Scholten, Sprachverbreitungspolitik des nationalsozialistischen Deutschlands, S. 397.

33 Barbian, Kulturwerte im Zweikampf, S. 430-439; für Rumänien Scholten, Sprachverbreitungspolitik des nationalsozialistischen Deutschlands, S. $354 \mathrm{f}$. 
mußte sehr zum Unwillen Münchens in Frankreich unter den Tisch fallen. Dort war die Akademie bis 1939 nicht tätig gewesen. Jetzt aber wurden hier innerhalb kürzester Zeit auf Betreiben der deutschen Botschaft in Paris und des dortigen Kulturinstituts unter Karl Epting zehn Lektorate mit der weitaus größten Zahl aller im Ausland tätigen Lektoren aus dem Boden gestampft. Allein in Paris waren 1942 zwanzig Lektoren im Einsatz, mehr als in jedem einzelnen der Balkanländer, die bislang den Schwerpunkt gebildet hatten. In Frankreich sollten sie sich auf Geheiß der Botschaft aus Gründen der Tarnung „Deutsches Institut“ nennen. Das gleiche galt in Italien. Damit sollte in jenen Ländern der Eindruck vermieden werden, bei den Lektoraten handele es sich um Außenstellen einer zentral gesteuerten Organisation. Ein weiterer Streitpunkt zwischen Auswärtigem Amt und Akademie ergab sich dadurch, daß Epting die Sprachkurse für die Hörer möglichst kostengünstig anbieten wollte, um das seit $1940 \mathrm{zu}$ verzeichnende starke Interesse der Franzosen an der deutschen Sprache optimal ausschöpfen zu können. Dies stand im Gegensatz zur von Thierfelder begründeten Tradition, keine Billigsprachkurse anzubieten, denn alles, was es mehr oder weniger umsonst gebe, gerate in den Geruch der Propaganda. ${ }^{34}$

Generalsekretär Fochler-Hauke gingen die Eingriffe des Auswärtigen Amts in die Arbeit der Akademie schließlich zu weit, obwohl er im Kleinen Rat im Dezember 1939 am nachdrücklichsten für eine Umwandlung der Akademie in eine öffentliche Einrichtung plädiert hatte. Er rückte im Juni 1941 erneut - er hatte sich bereits im Frühjahr 1940 für den Frankreichfeldzug gemeldet - freiwillig zur Wehrmacht ein, obwohl Siebert ihn davon abzuhalten versuchte. ${ }^{35}$ So sehr das Auswärtige Amt auch an der Intensivierung der Sprachwerbung im Ausland seit 1939 interessiert war, so wenig war der Wilhelmstraße an den Arbeiten der wissenschaftlichen Abteilung der Akademie gelegen. Gerade dieser jedoch fühlte sich Fochler-Hauke als frisch habilitierter Privatdozent der Münchener Universität, der im Gegensatz zu Thierfelder wenig Interesse an sprachpolitischen Fragen hatte, besonders verbunden.

\section{Umwandlung in eine Körperschaft des Öffentlichen Rechts}

Siebert, der im Dezember 1939 im Kleinen Rat und erneut im Mai 1940 vor dem Senat für den Erhalt der Akademie als eingetragenem Verein plädiert hatte, um die Wirksamkeit der Akademiearbeit nicht zu gefährden, ${ }^{36}$ ließ nach dem Sieg der Wehrmacht über Frankreich in dieser Hinsicht ebenfalls jede Zurückhaltung fal-

34 Michels, Das Deutsche Institut in Paris, S. $188 \mathrm{ff}$.

$35 \mathrm{Vgl}$. Fochler-Haukes Personalakte in BAB R51/101134. Damit nicht genug, FochlerHauke versuchte durch seine Beziehungen zu Siebert sicherzustellen, daß er auch tatsächlich in den Fronteinsatz kam. Sein Wunsch scheint in Erfüllung gegangen zu sein, denn er wurde im Herbst 1941 an der Ostfront schwer verwundet und verbrachte mehrere Wochen in Deutschland im Lazarett. Er nahm nie mehr seine frühere Tätigkeit in der Deutschen Akademie auf, sondern ging nach seiner Genesung erneut an die Front und kehrte erst 1945 aus dem Krieg zurück.

36 BAK N1160/I/142, Protokoll der Sitzung des Senats, 4. 5. 1940. 
len. Spätestens seit Anfang Oktober betrieb er zielstrebig die Umwandlung der Akademie in eine Körperschaft des Öffentlichen Rechts. ${ }^{37}$ Dadurch hoffte er, die Finanzierung der Deutschen Akademie und deren weiteren Ausbau auch über den Krieg hinaus sicherzustellen, der im Herbst 1940 so gut wie gewonnen schien. Die beabsichtigte Umwandlung der Akademie in eine Körperschaft des Öffentlichen Rechts, also zu einer Institution, die staatliche Aufgaben wahrnahm, erforderte es, den Auftrag der Akademie präziser zu definieren. „Siebert erläutert mir die Aufgaben der Deutschen Akademie. Er faßt die ganze Sache sehr energisch und großzügig an. Daraus kann noch etwas werden", notierte Goebbels am 1. November 1940 in seinem Tagebuch. ${ }^{38}$ Am nächsten Tag hielt Siebert Hitler in Berlin Vortrag über seine Pläne. Obwohl innerhalb der NS-Hierarchie an untergeordneter Stelle, erfreute sich Siebert bei Hitler dennoch eines hohen Ansehens. In einem seiner Monologe bezeichnete Hitler ihn beispielsweise als eine "hervorragende Persönlichkeit“, als einen „Rechenmeister“, der aber nicht unempfänglich gegenüber den Künsten sei. ${ }^{39}$ Hitler, der sich 1937 noch recht skeptisch über die Münchener Institution geäußert hatte, seinen Paladinen aber in der Regel im Zwiegespräch ungern einen Wunsch ausschlug oder ihre Initiativen abblockte, sofern sie nicht Kernbereiche wie die Außenpolitik und Kriegführung betrafen, ${ }^{40}$ zeigte sich laut Protokoll daher auch sehr interessiert an Sieberts Ausführungen und billigte die Vorschläge, u.a. die Idee, einen repräsentativen Neubau für die Akademie in München zu errichten. Neben der Umwandlung der Akademie in eine Körperschaft des Öffentlichen Rechts trug Hitler Sieberts Wunsch Rechnung, daß die Akademie zukünftig das Monopol der Sprachwerbung nicht nur im Ausland erhalten würde, sondern auch jenes der Förderung und Pflege der deutschen Sprache im Reich. Hierzu dürfe die Akademie eine Flurbereinigung unter den anderen dafür zuständigen Einrichtungen durchführen. Um Deutsch zur führenden Sprache Europas zu machen, willigte Hitler ferner ein, daß das RMEWV trotz des Lehrermangels in Deutschland die nötigen Sprachlehrer für das Ausland zur Verfügung zu stellen habe. Hitler forderte abschließend Siebert auf, einen Entwurf für einen die Akademie betreffenden „Führererlaß" vorzulegen. ${ }^{41}$

Wie großzügig man im Auswärtigen Amt und in der Akademie die Werbung für die deutsche Sprache in Europa im Herbst 1940 zu gestalten dachte, zeigt eine kurz nach der Unterredung zwischen Hitler und Siebert im RMEWV entstandene Aufzeichnung. Sie nennt die Zahl von ungefähr 1000 Lehrern, die das Auswärtige Amt in naher Zukunft allein nach Rumänien und Frankreich als Lektoren der

37 „Es ist eine nicht wegzuleugnende Tatsache, daß dieser Führererlaß ganz allein der Persönlichkeit und Tatkraft Ludwig Sieberts zu danken ist, " hieß es bei Sieberts Beerdigung im November 1942. Vgl. Wüst, Gedenkrede für den verstorbenen Präsidenten, S. 362.

38 Die Tagebücher von Joseph Goebbels. Teil I Aufzeichnungen 1923-1941, Bd. 4 (MärzNovember 1937), hrsg. von Elke Fröhlich im Auftrag des Instituts für Zeitgeschichte, München 2000, S. 381 .

39 Werner Jochmann (Hrsg.), Adolf Hitler. Monologe im Führerhauptquartier 1941-1944. Die Aufzeichnungen Heinrich Heims, Hamburg 1980, Aufzeichnung vom 17.12. 1941 (S. 154).

40 Ein Beispiel hierfür in Kershaw, Hitler 1889-1936, S. $537 \mathrm{f}$.

$41 \mathrm{BAB}$ R43/II/1230a, Schreiben Sieberts an Lammers, 2. 11. 1940. 
Deutschen Akademie zur Verbreitung der deutschen Sprache zu entsenden gedenke. Dies wäre in den Augen des Ministeriums ein pädagogischer Aderlaß gewesen, den das deutsche Schulwesen, das ohnehin seit den dreißiger Jahren unter starkem Lehrermangel litt, unmöglich verkraften konnte. Abhilfe könne höchstens die Kreation des Berufes eines „staatlichen Sprachlehrers“ schaffen.42 Mitte Dezember 1940 hielt Siebert in Stuttgart im DAI eine Rede, in der er erneut öffentlich forderte, daß Deutsch zu der in der Welt geltenden Sprache gemacht werde. Im Mittelalter sei Latein Verständigungsmittel der Gebildeten gewesen, seit 1789 habe zunächst Französisch als die hinter der Idee der französischen Revolution stehende Sprache dominiert und schließlich im Zeitalter des liberalen Welthandels Englisch. Nun, im Zeitalter der nationalsozialistischen Revolution und der von ihr ausgehenden Triebkräfte zur Neuordnung Europas schlage die Stunde der deutschen Sprache. ${ }^{43}$

Die Planungen zur Umwandlung der Deutschen Akademie in eine Körperschaft des Öffentlichen Rechts seit Herbst 1940 waren Bestandteil eines sich Ende 1940 abzeichnenden Versuchs des NS-Regimes, in Hinblick auf die deutsche Sprache eine Politik zu formulieren, welche im Inland ihren Gebrauch vereinheitlichen und damit auch ihrer Erlernung und Verbreitung im Ausland förderlich sein würde. Eine weitere Initiative, die etwa zeitgleich erfolgte, war das Verbot des „Sprachpurismus" durch Hitler in einem „Führererlaß" vom 19. November 1940. Damit sollte der bislang vor allem vom 1885 gegründeten „Allgemeinen Deutschen Sprachverein" exzessiv betriebenen Jagd auf Fremdwörter im deutschen Wortschatz und ihre Ersetzung durch z.T. kuriose Neuschöpfungen rein "germanischen" Ursprungs wie etwa "Rauchrolle“ an Stelle von „Zigarre“ ein Riegel vorgeschoben werden. Der Sprachverein hatte es sich schon früh mit den führenden Vertretern des NS-Regimes, allen voran Goebbels, verdorben, da er es bis Mitte der dreißiger Jahre wagte, den Sprachgebrauch der neuen Elite zu kritisieren. Dieser sei noch von zu vielen Fremdwörtern durchsetzt, nicht zuletzt dem Doppelfremdwort „Nationalsozialismus“, während doch in den Augen des Sprachvereins die neue politische Führung Vorbild für einen wahrhaft „deutschen“ Sprachgebrauch sein sollte. ${ }^{44}$ Zudem fügte sich in diese sprachpolitische Entwicklung das Frakturverbot Martin Bormanns vom 3. Januar 1941, das für Staats- wie Parteiinstitutionen den Gebrauch der Antiquaschrift verbindlich festlegte. Die gebrochenen Schriftzeichen hingegen, die in Deutschland bislang stets in Zeiten nationalchauvinistischer Hochstimmung wie etwa im Ersten Weltkrieg und während der „nationalen Revolution“" von 1933 als die „wahrhaft deutsche Schrift" in

42 Vermerk des RMEWV vom 7. 11. 1940, abgedruckt in: Otfried Dankelmann, Aus der Praxis auswärtiger Kulturpolitik des deutschen Imperialismus, in: Zeitschrift für Geschichtswissenschaft, 20 (1972), S. 719-737, hier S. 734 f.

43 Hamburger Tageblatt, 15. 12. 1940.

44 Vgl. Peter von Polenz, Sprachpurismus und Nationalsozialismus. Die Fremdwortfrage gestern und heute, in: Germanistik - eine deutsche Wissenschaft. Beiträge von Eberhard Lämmert, Walter Killy u.a., Frankfurt/M. 1967, S. 111-165; Tozo Hayakawa, Die Fremdwortfrage und der Deutsche Sprachverein in der NS-Zeit, in: Deutsch als Fremdsprache. An den Quellen eines Faches. Festschrift für Gerhard Helbig zum 65. Geburtstag, hrsg. von Heidrun Popp, München 1995, S. 429-436. 
Druckerzeugnissen auf Kosten der lateinischen Lettern bevorzugt Verwendung fanden, ${ }^{45}$ wurden nunmehr paradoxerweise als „Schwabacher Judenlettern“ diffamiert. Dabei sollten zunächst die auf das Ausland abzielenden Presseerzeugnisse auf die nun als „Normalschrift" bezeichneten lateinischen Lettern umgestellt werden. Damit entschied das Regime die seit dem 18. Jahrhundert ausgetragene Diskussion, ob die lateinische oder die gotische Schrift die der deutschen Sprache angemessene sei, zumindest für den amtlichen Schriftverkehr im Sinne einer „ausländerfreundlichen" Regelung, welche die Durchsetzung von Deutsch als führende Sprache auf dem europäischen Kontinent erleichtern würde. ${ }^{46}$ Auch wenn in den erhaltenen Akten kein Hinweis auf die Verknüpfung von den Bemühungen zur Erhebung der Deutschen Akademie zu einer Körperschaft des Öffentlichen Rechts mit dem in etwa zeitgleichen Verbot des Sprachpurismus und dem Gebot der Nutzung der Antiquaschrift zu finden ist, so lancierte zweifellos Siebert seine Initiative in einem günstigen Moment. Getragen vom Hochgefühl des Sieges über Frankreich und der in greifbare Nähe gerückten Dominanz über den Kontinent, standen die Zeichen im NS-Staat auf eine sprach- und schriftpolitische Flurbereinigung.

Der erste Satzungsentwurf für die Deutsche Akademie als Körperschaft des Öffentlichen Rechts zur Jahreswende 1940/41 sah noch die Dienstaufsicht des Auswärtigen Amts vor, da von Ribbentrop Siebert sein Interesse an der Deutschen Akademie bezeugte und ihm versicherte, das Auswärtige Amt habe noch große Pläne mit ihr. ${ }^{47}$ Auch das Auswärtige Amt hatte also keine Vorbehalte mehr dagegen, daß der Verein sich in eine staatliche Körperschaft des Öffentlichen Rechts verwandeln sollte. Dies ist insofern aufschlußreich, als bis Ende der dreiBiger Jahre vom Auswärtigen Amt immer wieder der Nutzen betont worden war, den die Kulturpolitik daraus ziehe, daß sie in wichtigen Bereichen von anscheinend unabhängigen und daher dem Ausland unverdächtigen privaten Vereinen betrieben werde. Im Zeichen der Siege der Wehrmacht glaubte man offenbar in Berlin ebenso wie in München einer solchen Tarnung der Kulturpolitik zukünftig nicht mehr zu bedürfen.

Der Anspruch des Auswärtigen Amts auf Dienstaufsicht über die zu schaffende neue Körperschaft brachte das Propagandaministerium auf den Plan, das nach wie vor die Führungsrolle der Wilhelmstraße in der Auslandspropaganda bestritt. Dabei war das Propagandaministerium offenbar nicht so sehr wie das Auswärtige Amt an der Verbreitung der deutschen Sprache im Ausland als Ziel an sich gemäß der Vorgabe „Weltsprache Deutsch“ interessiert. Vielmehr sah es eine möglichst große Zahl von Deutsch sprechenden Menschen als unabdingbare Voraussetzung

45 Am Vorabend des Ersten Weltkriegs wurden in Deutschland etwa 56\% aller Schriften in Fraktur gedruckt, zwischen 1914 und 1918 hingegen etwa 66\%. Bis 1932 fiel der Anteil der Fraktur auf knapp 45\%, um bis 1934 wieder auf über $57 \%$ anzusteigen. Zahlen aus Franz Thierfelder, Deutsche Schriftfragen im Auslandsunterricht, in: Deutschunterricht im Ausland, Heft 4 (Dezember 1937), S. 5 f.

46 Vgl. Peter Reich, Die Sprache der Schrift. Zur Geschichte des Frakturverbots von 1941, in:

Homo scribens. Perspektiven der Schriftlichkeitsforschung, hrsg. von Jürgen Baumann u. a., Tübingen 1993, S. 231-272.

47 BAB R55/177, Aufzeichnung für Goebbels von Ministerialrat Ziegler, 2. 1. 1941. 
für eine erfolgreiche europaweite Propagandatätigkeit, die Deutsche Akademie also nur als ein hilfreiches Instrument zur Verbreitung politischer Botschaften. Nur deshalb setzte sich das Propagandaministerium beispielsweise auch für Deutschkurse unter den im Reich tätigen Zwangsarbeitern ein. Sie sollten nicht nur einen Beitrag zur Kriegswirtschaft leisten, sondern nach dem Krieg als Träger deutscher Propagandaparolen in ihre Heimatländer zurückgehen und dort aufgrund ihrer erworbenen Deutschkenntnisse leichter beeinflußbar bleiben..$^{48}$

Auch das RMEWV schaltete sich ein. Es forderte die Dienstaufsicht für sich, da es sich bei der Akademie immer noch offiziell um eine wissenschaftliche Einrichtung handelte. Allerdings erwies sich sein Amtschef Rust, dessen Stellung im Machtgefüge des Dritten Reiches relativ schwach war, ${ }^{49}$ in dieser Auseinandersetzung um die Aufsicht über die neue Körperschaft letztlich chancenlos. Schließlich meldete sich auch Alfred Rosenberg zur Jahreswende 1940/41 zu Wort. Er sah die Akademie als Konkurrenz zu der von ihm anvisierten "Hohen Schule“, die eine Art NS-Wissenschaftskaderschmiede werden sollte, für die er von Hitler im Januar 1940 grünes Licht bekommen hatte. Rosenberg stieß sich vor allem an der weitgefaßten Formulierung des $\$ 2$ des Satzungsentwurfs, der die Aufgabe der Akademie recht allgemein mit der Erforschung und Pflege des deutschen Kulturgutes in Vergangenheit und Gegenwart umschrieb, wobei ihr insbesondere die Erforschung und Pflege der deutschen Sprache im Inland und Förderung und Verbreitung im Ausland obliege. ${ }^{50}$ Zwar gelang es Rosenberg, neben Hitler offiziell der Chefideologe des Dritten Reiches, dessen tatsächliche Stellung im Machtgefüge des NS-Regimes aber nie seinem Anspruch auf eine geistige wie kulturelle Führerschaft entsprach, ${ }^{51}$ nicht, Einfluß auf die Akademie zu gewinnen oder die „Hohe Schule“ bis Kriegsende tatsächlich zu gründen. Aber sein Einspruch vom Januar 1941 war vermutlich dafür ausschlaggebend, daß in der Endversion des „Führererlasses“ über die Deutsche Akademie der ursprünglich weit gefaßte Auftrag zur Erforschung und Pflege des deutschen Kulturgutes in Vergangenheit und Gegenwart wesentlich restriktiver formuliert war.

Wegen dieser Kompetenzstreitigkeiten hinter den Kulissen vor allem zwischen Auswärtigem Amt und Propagandaministerium zogen sich die Vorarbeiten für den endgültigen „Führererlaß“ bis zum Herbst 1941 hin. Ein weiterer Grund für die Verzögerung war der Umstand, daß Siebert, der offenbar Gefallen an der Tätigkeit als Akademiepräsident gefunden hatte, hartnäckig an dem Anspruch festhielt, die neue Körperschaft solle unbedingt ihren Charakter als wissenschaftliche

48 So jedenfalls die Ausführungen des im Propagandaministerium für die Deutsche Akademie zuständigen Referenten Ziegler auf der Tagung der Leiter der Reichspropagandaämter im Juli 1942 in Berlin, in: IfZ FA 511, Vortrag Prof. Ziegler, S. 25-29.

49 Karl-Dietrich Bracher, Die deutsche Diktatur. Entstehung, Struktur, Folgen des Nationalsozialismus, Berlin 1997, S. $378 \mathrm{ff}$.

50 IfZ MA 544, Satzungsentwurf für die Deutsche Akademie vom Januar 1941 mit handschriftlichem Vermerk, Rosenberg habe am 27.1. 1941 gegen diesen bei Heß Einspruch erhoben (Bl. 462f.) sowie Schreiben Rosenbergs vom 20.3. 1941 an Bormann (Bl. 335337).

51 Hierzu grundlegend Reinhard Bollmus, Das Amt Rosenberg und seine Gegner. Studien zum Machtkampf im nationalsozialistischen Herrschaftssystem, Stuttgart 1970. 
Akademie wahren. Dies war ein Aspekt ihrer bisherigen Tätigkeit, an dem weder die konkurrierenden Ministerien noch die Reichskanzlei interessiert waren. Siebert beklagte sich denn auch gegenüber dem Chef der Reichskanzlei, Hans Heinrich Lammers, im Juni 1941 über die geplante „Herabwürdigung der Deutschen Akademie zu einem Sprachinstitut“. Frustriert darüber, daß seine Neuordnungspläne auf die lange Bank geschoben wurden, erklärte Siebert am 24. Juli 1941 schließlich seinen Rücktritt als Präsident der Akademie. Er nahm ihn aber wieder zurück, als Lammers ihn auf die Arbeitsüberlastung Hitlers wegen des Angriffs auf die Sowjetunion hinwies, dem der „Führer" derzeit seine ganze Energie widmen müsse. ${ }^{52}$ Hierfür hatte der getreue Gefolgsmann natürlich vollstes Verständnis und ließ sich erneut vertrösten.

Im Oktober 1941 einigten sich schließlich Auswärtiges Amt und Propagandaministerium im Zuge des Versuchs der generellen Kompetenzabklärung auf dem Gebiet der Auslandspropaganda, der Ausdruck in einem entsprechenden Abkommen zwischen beiden Ministerien vom 22. Oktober 1941 fand, auf die gemeinsame Dienstaufsicht über die Deutsche Akademie, wobei das Auswärtige Amt zukünftig die Etatverhandlungen mit dem Reichsfinanzministerium führen solle. ${ }^{53}$ Dieses Abkommen revidierte in gewisser Weise die Führungskompetenz in der Auslandspropaganda, die der Wilhelmstraße noch am 8. September 1939 von Hitler zugesprochen worden war. Mittlerweile war die Stellung des Außenministers im Vergleich zu der von Goebbels wesentlich geschwächt worden. Goebbels, dessen Ruf bei Hitler bei Kriegsausbruch vor allem durch seine Affäre mit der Schauspielerin Baarova lädiert gewesen war, während sich von Ribbentrop ganz im Erfolg des soeben von ihm unterzeichneten deutsch-sowjetischen Nichtangriffspakts sonnte, hatte inzwischen wieder Hitlers Wohlwollen erlangt. Umgekehrt war die Stellung des Auswärtigen Amts durch die Ausweitung des Krieges, vor allem seit dem Angriff auf die Sowjetunion, der von Ribbentrops außenpolitisches Alternativkonzept eines antibritischen Kontinentalblocks unter Einschluß der UdSSR endgültig obsolet gemacht hatte, ${ }^{54}$ immer schwächer geworden: Die Zeichen standen nun überall auf militärischen Konfrontationen und nicht mehr auf diplomatischen Verhandlungen. Ein heftiger Zusammenstoß zwischen Ribbentrop und Hitler am 28. Juli 1941, der sich an einer Lappalie entzündete, ruinierte die Stellung des Außenministers bei Hitler endgültig. ${ }^{55}$

Siebert selbst zog spätestens seit Sommer 1941 ebenfalls die Dienstaufsicht des Propagandaministeriums vor, da sich bereits an der Auslandsarbeit, insbesondere im neuen Schwerpunktland Frankreich, zeigte, in welch eingeschränktem Maße die Deutsche Akademie unter der Aufsicht des Auswärtigen Amts würde arbeiten können. Zudem hatte das Auswärtige Amt noch deutlicher sein Desinteresse an

52 Harvolk, Eichenlaub und Hakenkreuz, S. 43.

53 Eine Kopie befindet sich in: PA Bd. R60607.

54 Vgl. hierzu Wolfgang Michalka, Ribbentrop und die deutsche Weltpolitik 1933-1940. AuBenpolitische Konzeptionen und Entscheidungsprozesse im Dritten Reich, München 1980, S. $278 \mathrm{ff}$.

55 Vgl. Longerich, Propagandisten im Krieg, S. $142 \mathrm{ff}$. Zum Zusammenstoß zwischen Hitler und Ribbentrop am 28. 7. 1941 siehe Bloch, Ribbentrop, S. $338 \mathrm{f}$. 
dem wissenschaftlichen Auftrag der Akademie geäußert als das Propagandaministerium. ${ }^{56} \mathrm{Daß}$ man in der Akademie zunehmend gereizter auf die Eingriffe des Auswärtigen Amts reagierte und schließlich beinahe die Dienstaufsicht des Propagandaministeriums herbeisehnte, zeigt eine Reihe von Briefen von Walter Kunze, dem Sekretär der wissenschaftlichen Abteilung, an den im Lazarett liegenden Fochler-Hauke zur Jahreswende 1941/42, in denen er diesen über die Vorgänge in der Akademie auf dem laufenden hielt. So schrieb er am 24. Oktober 1941, die in Berlin vor einigen Wochen zwischen Siebert, von Twardowski und von Weizsäcker geführten Gespräche hätten dazu geführt, daß dem Hineinreden des Auswärtigen Amts in die wissenschaftlichen Arbeiten der Akademie ein energisches „Halt" vorgebaut worden sei. ${ }^{57}$

Am 15. November 1941 unterzeichnete Hitler schließlich den „Führererlaß“, 58 der hinsichtlich der Dienstaufsicht den Wünschen Sieberts folgte und damit auch vom Ansehensverlust Ribbentrops bei Hitler zeugte. Das Propagandaministerium erhielt laut $\$ 6$ die Dienstaufsicht, das Auswärtige Amt konnte allerdings Auflagen und Richtlinien hinsichtlich der Auslandsarbeit erteilen - eine scheinbar salomonische Lösung, die jedoch weitere Konflikte zwischen beiden Ministerien vorausahnen ließ. $\$ 2$ Absatz 1 verpflichtete die neue Körperschaft auf die Sprachpflege und Sprachforschung im Inland sowie ihre Förderung und Verbreitung im Ausland. Damit war nicht nur eine Zentralinstitution in Deutschland zur Förderung der deutschen Sprache im Ausland etabliert worden. Erstmals entstand zumindest auf dem Papier auch eine zentrale, staatlich geförderte Sprachnormierungsinstanz. Forderungen nach einer solchen waren seit dem frühen 17. Jahrhundert, als sich in Weimar die „Fruchtbringende Gesellschaft" konstituierte, in Deutschland wiederholt mit Blick auf das Vorbild der Académie Française erhoben worden. Sie waren aber bislang stets entweder am Widerstand der bereits etablierten Akademien, am Desinteresse staatlicher Institutionen oder am Unwillen der gebildeten Öffentlichkeit in Deutschland, die sich nicht einem zentralistischen Sprachdiktat nach französischem Muster unterwerfen wollte, gescheitert. ${ }^{59} \mathrm{Die}$ früheren Ambitionen, auch als wissenschaftliche Akademie in Erscheinung zu treten, welche die Kultur Deutschlands umfassend erforschen und dokumentieren sollte, wurden hingegen im Erlaß zurechtgestutzt. Im zweiten Absatz von $§ 2$, der den Sinn und Zweck der Akademie definierte, hieß es nur noch: „Außerdem nimmt die Deutsche Akademie an der Erforschung und Pflege des deutschen Kulturgutes in Vergangenheit und Gegenwart teil." Dennoch schrieb Kunze an Fochler-Hauke, daß Präsident Siebert über den „Führererlaß“ „sehr glücklich“ sei,

56 BAB R43/II/1230a, Schreiben Sieberts an Lammers, 22. 7. 1941.

57 BAB R51/101134.

58 Reichsgesetzblatt 1941, Teil I, S. 717 f.

59 Zu nennen wären u. a. Gottfried Wilhelm Leibniz' Anregungen am Ende des 17. Jahrhunderts, sodann die in diese Richtung zielenden Vorschläge von Karl Gustav Heräus 1721, Georg Litzel 1730, Gottfried Herder 1783, Ludwig Uhland 1817, die Überlegungen Leopold von Rankes zwischen 1859 und 1871, die wiederholten Vorschläge des Allgemeinen Deutschen Sprachvereins ab 1885, schließlich die Initiative des Kaufmannns Heinrich Krohn ab 1888, der bereit war, hierfür 500000 RM zu stiften und des Gießener Germanisten Otto Behagel 1901. Vgl. hierzu Flamm, Eine deutsche Sprachakademie? 
„und die Formulierung für uns wider Erwarten günstig ist““.60 Der Erlaß ließ also entgegen andersartiger Befürchtungen im Vorfeld in München der Akademie ein Tor offen zu weiterer wissenschaftlicher Forschung.

\section{Die Folgen des „Führererlasses“}

Aus Anlaß der Umwandlung der Deutschen Akademie in eine Körperschaft des Öffentlichen Rechts steckte Siebert in einer Ansprache am 1. Dezember 1941 erneut öffentlich die sprachpolitischen Ziele der Deutschen Akademie ab:

„Wir wollen der deutschen Sprache als einer Weltsprache den ihr gebührenden Platz erobern helfen. Wer mit dem großen Deutschland an einem Tisch sitzen will, der muß der deutschen Sprache bei Verhandlungen diplomatischer, wissenschaftlicher, kultureller und gesellschaftlicher Art mindestens die gleiche Bedeutung zugestehen wie seiner eigenen. Die Deutsche Akademie wird daher die deutsche Sprache mit aller Macht zu erforschen, zu pflegen, zu fördern und zu verbreiten bemüht sein." 61

Diese Forderung deckte sich erneut mit den Überlegungen des Auswärtigen Amts, das z. B. im Sommer 1942 seine Missionen in Europa darauf verpflichtete, im Schriftverkehr mit den Behörden der jeweiligen Gastländer ausschließlich die deutsche Sprache zu verwenden. ${ }^{62}$ Siebert konnte bei seinen sprachpolitischen Plänen zudem ganz auf Hitler setzen. Denn auch dieser sah im November 1941 Deutsch als die in hundert Jahren allgemein in Europa verbreitete Sprache an, welche alle Völker erlernen würden, um sich mit dem Reich verständigen zu können. Um ihre Erlernung zu erleichtern, verkündete er in einem seiner nächtlichen Monologe im „Führerhauptquartier“, sei es ein vernünftiger Schritt gewesen, die gotische Schrift zu verbieten. Ein halbes Jahr später hielt er es zudem für angebracht, die Dialekte in Deutschland verkümmern zu lassen, um den Ausländern ein möglichst einheitliches Deutsch vermitteln zu können. ${ }^{63}$

Am 2. Dezember besprach Siebert mit Goebbels die weitere Ausgestaltung der Akademie. Letzterer notierte daraufhin in seinem Tagebuch:

„Ich möchte aus der Deutschen Akademie ein wirkliches geistiges Führungspodium machen. Siebert hat große Pläne in diese Richtung. Wir wollen uns beim Aufbau der Deutschen Akademie nicht durch die Eifersüchteleien des Auswärtigen Amtes beirren lassen. Das Auswärtige Amt möchte trotz des letzten Führererlasses immer noch in die Sache hineinfuhrwerken; aber ich werde das zu verhindern wissen. Ministerialrat Ziegler soll demnächst zum Vizepräsident ernannt werden, und damit ist ja die Verbindung zum Promi sehr fest und unlösbar geknüpft." 64

60 BAB R51/10134, Brief Kunzes and Fochler-Hauke, 25. 11. 1941.

61 Ansprache des Ministerpräsidenten Ludwig Siebert anläßlich der Neuordnung der Deutschen Akademie am 1.12. 1941, in: Deutsche Kultur im Leben der Völker (MdDA), 16 (1941), S. 372-374, hier S. 373.

62 Scholten, Sprachverbreitungspolitik des nationalsozialistischen Deutschlands, S. 58.

63 Jochmann, Monologe im Führerhauptquartier, Aufzeichnungen vom 2.11. 1941 (S. 124) und vom 21. 8. 1942 (S. 359L).

64 Die Tagebücher von Joseph Goebbels. Teil II Diktate 1941-1945, Bd. 2 (Oktober-Dezember 1941), hrsg. von Elke Fröhlich im Auftrag des Instituts für Zeitgeschichte, München 1996, S. 417. 
Auch Kunze berichtete im Januar 1942 an Fochler-Hauke, daß trotz des „Führererlasses" das Hauen und Stechen um die Einflußnahme auf die Akademie im Hintergrund weitergehe, wobei nicht nur das Auswärtige Amt auf der fortgesetzten Kontrolle der Auslandsarbeit beharre, sondern auch das Amt Rosenberg sich wieder zu Wort gemeldet und einen Vorstoß gegen die wissenschaftliche Abteilung geführt habe, der aber leicht zurückgewiesen worden sei. Das RMEWV hingegen akzeptiere die Weichenstellung vom November 1941 und setze fortan auf Kooperation mit der neuen Körperschaft. So habe es bereits im Januar 1942 zwei hohe Beamte nach München entsandt, um zukünftig die Akademie bei der Auswahl der ins Ausland zu entsendenden Universitätslektoren zu beteiligen und sie stärker in den Deutschunterricht für ausländische Studenten an den Hochschulen des Reiches einzubinden. 65

Tatsächlich änderte sich aber für die Deutsche Akademie nach dem „Führererlaß" in der Auslandsarbeit nicht viel. Der Etat für die Auslandsarbeit wurde weiterhin vom Auswärtigen Amt mit dem Reichsfinanzministerium ausgehandelt. Das Auswärtige Amt hatte nach wie vor das letzte Wort bei der Dislozierung der Lektorate und der über die reine Spracharbeit hinausgehenden Kulturwerbung in den Lektoraten. Ferner konnte das Auswärtige Amt Auflagen bezüglich der zu entsendenden Lektoren machen. Die gesamte Berichterstattung mußte wie zuvor über die Auslandsmissionen laufen. Dieser Kompromiß wurde schließlich in einem Arbeitsabkommen zwischen Propagandaministerium und Auswärtigem Amt über die Deutsche Akademie am 1. August 1942 auch schriftlich fixiert, das nunmehr eine detaillierte Zuständigkeitsabgrenzung, die durch den $\$ 6$ des „Führererlasses" notwendig geworden war, mit einiger Verzögerung versuchte. 66

In finanzieller Hinsicht machte sich das Interesse der beiden Ministerien für die Deutsche Akademie im wahrsten Sinne des Wortes bezahlt. 1942 stieg der Haushalt der Deutschen Akademie auf 7 Millionen RM, davon kamen 5,5 Millionen RM vom Auswärtigen Amt und erstmalig 700000 RM vom Propagandaministerium. Der Rest waren Spenden aus der Wirtschaft in Höhe von 400000 RM und Eigeneinnahmen durch die Sprachkurse im Ausland. Im Jahre 1944 erreichte der Haushalt der Deutschen Akademie schließlich die Rekordhöhe von 9,05 Millionen RM. Davon wurden mehr als 7 Millionen RM vom Reich zur Verfügung gestellt. Das Personal in der Hauptstelle in München wurde angesichts dieses Geldsegens bis 1944 ausgebaut. Ende 1943 waren in der Abteilung Auslandslektorate unter Nitschke 11 Personen beschäftigt, im Goethe-Institut unter Derleth zehn und in der Zentralverwaltung neun Kräfte. Ferner gab es noch ein 1940 eingerichtetes Verbindungsbüro der Akademie in Berlin mit vier Angestellten.67

65 BAB R51/101134, Brief Kunzes an Fochler-Hauke, 28. 1. 1942.

66 BAB R55/17, Arbeitsabkommen über die Deutsche Akademie, 1. 8. 1942.

67 Zahlen für Ende 1943 in: BAB R51/8, Bericht über den Stand der Deutschen Akademie, 31. 12. 1943. 


\section{Die Grenzen der Auslandsarbeit}

Das Auswärtige Amt hielt unbeirrt vom Tauziehen um die Kontrolle der Akademie an dem Vorsatz fest, die Spracharbeit im Ausland großzügig auszubauen. Im Herbst 1942 erreichte die Zahl der von München entsandten Lehrkräfte den historischen Höchststand von 198 Personen in 100 Lektoraten. Unterstützt wurden sie von etwa 500 Hilfslehrkräften vor Ort, die weitere 158 sogenannte Zweigstellen der Lektorate in den kleineren Provinzstädten des verbündeten und besetzten Europas betrieben. Dies war natürlich nur ein schwacher Abglanz der großartigen Pläne, die man für die Auslandsspracharbeit im Sommer 1940 in München wie Berlin gehegt hatte. Der Rückgriff auf lokale Kräfte, oftmals Volksdeutsche oder im Ausland lebende Reichsdeutsche, z.T. auch Wehrmachtsangehörige, war eine Notlösung: Seit 1941 war das Hauptproblem der Akademie nicht mehr das Geld, sondern das Personal. Im Winter 1941 gab es bereits eine erste personelle Krise, ausgelöst durch die hohen Verluste der Wehrmacht seit Beginn des Angriffs auf die Sowjetunion, die in der sogenannten Winterkrise, also dem Steckenbleiben der deutschen Offensive vor Moskau und dem sowjetischen Gegenangriff ab Anfang Dezember kulminierte. Auf Drängen der Wehrmacht widerrief Hitler am 23. Dezember 1941 die bislang mit Rücksicht auf die Stimmung an der Heimatfront großzügig gehandhabte Unabkömmlichkeitsstellung weiter Kreise der männlichen wehrfähigen Bevölkerung, ${ }^{68}$ die bislang u.a. für alle männlichen Lektoren gegolten hatte. Folglich wurden in München bereits Überlegungen angestellt, ob man nicht angesichts der zu erwartenden Einberufungen die Spracharbeit in einigen als weniger wichtig angesehenen Ländern wie der Slowakei notfalls einschränken solle, um sie an anderen, wichtigeren Plätzen wie Frankreich und im neutralen Ausland ungemindert fortführen zu können. Auch das RMEWV, ohnehin vom Lehrermangel geplagt, stellte so gut wie keine Lehrer mehr vom Schuldienst für den Auslandseinsatz frei, berichtete Kunze im Januar 1942 an FochlerHauke.69

Wenn es schließlich auch zu keiner Reduzierung der Auslandsarbeit durch die "Winterkrise“ kam, so behinderte doch fortan der Personalbedarf der Wehrmacht die sprachpolitischen Pläne Münchens und Berlins. Fast 1,4 Millionen RM des für 1942 genehmigten Haushaltes der Akademie mußte München schließlich an das Reichsfinanzministerium zurücküberweisen, da aus Mangel an geeignetem Personal im Jahre 1942 der Ausbau des Lektoratsnetzes nicht in dem Maße möglich gewesen war wie ursprünglich projektiert. ${ }^{70}$ Eine der "Notlösungen“, welche die Akademie in dieser Situation ersann, war der vermehrte Rückgriff auf Lektorinnen, deren Anteil von etwa 5\% unter den Auslandsmitarbeitern im Jahre 1939 auf

68 Vgl. hierzu Bernhard R. Kroener, Die personellen Ressourcen des Dritten Reiches im Spannungsfeld zwischen Wehrmacht, Bürokratie und Kriegswirtschaft 1939-1942, in: Das Deutsche Reich und der Zweite Weltkrieg. Teilband 5/1 Kriegsverwaltung, Wirtschaft und personelle Ressourcen 1939-1941, hrsg. vom Militärgeschichtlichen Forschungsamt, Stuttgart 1988, S. 693-1017, hier S. $871 \mathrm{ff}$.

69 BAB R51/101134, Brief Kunzes an Fochler-Hauke, 28. 1. 1942.

70 BAB R2/4780. 
schließlich etwa 30\% im Sommer 1944 stieg. Allerdings standen ideologische Vorbehalte einer stärkeren Ausschöpfung des weiblichen Reservoirs entgegen. Obwohl der Leiter der Abteilung Auslandslektorate durchaus die Leistungen der weiblichen Lehrkräfte anerkannte, blieb es für ihn eine kriegsbedingte Abweichung von der Norm, die möglichst in Grenzen gehalten werden sollte. „Die Frau ist nur bedingt einsetzbar", verkündete Nitschke auf der Mittelstellenleitertagung im Februar 1944 in München. ${ }^{71}$ So erlaubte man Frauen weder, die Leitung eines Lektorates zu übernehmen oder an Einzellektoraten zu arbeiten, noch war man willens, sie in alle Länder zu entsenden. Die Lektorinnen kamen vor allem in Frankreich zum Einsatz. Die gleiche Haltung nahm im übrigen auch der Generalsekretär gegenüber der im Verlaufe des Krieges wachsenden Anzahl weiblicher wissenschaftlicher Kräfte in München ein. Er erkannte ihre Leistungen zwar an, hielt aber ihre Ersetzung durch männliche Kräfte für wünschenswert, so bald es die Umstände erlauben würden. ${ }^{72}$

Seit Kriegsausbruch legte die Deutsche Akademie mehr Wert auf Parteikonformität ihrer neuen Lektoren als zuvor. Die NSDAP ihrerseits ließ der Auswahl und Aktivität der Lektoren mehr Aufmerksamkeit als bislang zukommen. Bereits für die Entsendung einer Lehrkraft ins Ausland mußte nach Kriegsausbruch ein positives politisches Gutachten der Auslandsorganisation der NSDAP vorliegen. ${ }^{73}$ Die Deutsche Akademie mußte sich 1941 grundsätzlich bereit erklären, ihre Lektoren für eine aktive politische Arbeit im Ausland zur Verfügung zu stellen. ${ }^{74}$ Doch konnten sich die Lektoren, wenn sie denn wollten, dieser Vereinnahmung z. T. unter dem Hinweis entziehen, eine offensichtliche Kooperation mit der Auslandsorganisation gefährde die Wirksamkeit ihres kulturpolitischen Auftrages im Gastland. ${ }^{75}$ Der Einfluß der Auslandsorganisation der NSDAP auf die Auswahl neuer Lektoren beschränkte sich wohl vor allem darauf, dem Nationalsozialismus offensichtlich reserviert gegenüberstehende Kandidaten auszusieben. Allein schon der Mangel an geeigneten Kräften im Kriege zwang zu einer gewissen Nachsicht hinsichtlich der anzulegenden politischen Maßstäbe. Anders ist die Klage des Landesgruppenleiters der Auslandsorganisation in Frankreich, viele der Lektoren hätten eine zu starke kirchliche Bindung, nicht zu verstehen. Etwa die Hälfte der in Frankreich eingesetzten Lektoren stufte er in Hinblick auf einen Einsatz nach Kriegsende als ungeeignet ein. ${ }^{76} \mathrm{Da}$ der Akademie ein Teil ihres Auslandspersonals nicht aktivistisch genug eingestellt war, man dies aber in Ermangelung anderer geeigneter Mitarbeiter hinnehmen mußte, zeigt auch eine Äußerung des Generalsekretärs im November 1944, die vermutlich mehr als reiner Zweckoptimismus war. Er bezeichnete bei einer Mitarbeiterbesprechung die seit

71 BAB R51/26, Protokoll der Tagung der Mittelstellenleiter, 11.-16. 2. 1944.

72 BAB R51/8, Bericht über den Stand der Deutschen Akademie für Vizepräsident Wüst von Generalsekretär Schmitz, 23. 12. 1943.

73 BAB R51/5, Aufzeichnung Nitschkes für den Generalsekretär, 6. 8. 1941.

74 BAB R51/59, Abkommen zwischen der Auslandsorganisation der NSDAP und der Deutschen Akademie, 4. 12. 1941.

75 Scholten, Sprachverbreitungspolitik des nationalsozialistischen Deutschlands, S. $240 \mathrm{f}$, nennt ein Beispiel für Ungarn.

76 Michels, Das Deutsche Institut, S. 193. 
Sommer 1944 eingetretene Verringerung der Lektorenschaft durch Einberufungen zur Wehrmacht als „Reinigungsprozeß“, denn „fest steht, daß noch eine Reihe von Mitarbeitern im Ausland tätig war, die sich nicht als Lektoren eignete". .77

Trotz des Personalmangels stieg die Zahl der Sprachkursteilnehmer dank dem Ausbau des Zweigstellennetzes und dem Nutzen, den sich viele Europäer von der Erlernung der deutschen Sprache erhofften, so lange der Ausgang des Krieges noch nicht eindeutig zu sein schien. Im Herbst 1941 waren es etwa 49000 Hörer. Im Herbst 1942 erreichte die Akademie mit 64000 eingeschriebenen Hörern in drei neutralen (Portugal, Spanien, Schweden), sieben verbündeten (Italien, Bulgarien, Rumänien, Ungarn, Kroatien, Slowakei, Finnland) und fünf besetzten europäischen Staaten (Serbien, Frankreich, Griechenland, Belgien, Dänemark) sowie China und Argentinien als einzigen nach Kriegsausbruch verbliebenen überseeischen Posten die größte Breitenwirkung in ihrer Geschichte. Allein in Frankreich schrieben sich 1942 für die im Oktober beginnenden Kurse etwa 15000 Hörer ein.

Der Anstieg der Hörerzahlen seit Kriegsausbruch war nicht nur auf das verbesserte Angebot zurückzuführen. Vielmehr bewirkte die vorübergehende deutsche Dominanz auf dem Kontinent, daß sich offenbar mehr Europäer denn je für die deutsche Sprache interessierten, und sei es nur, um mit der Besatzungsmacht Geschäfte machen zu können. Im besetzten Frankreich beispielsweise hatte man in den ersten zwei Jahren Mühe, den Ansturm der Franzosen auf die neueingerichteten Sprachkurse zu bewältigen. Das Gleiche galt für das besetzte Griechenland, wo im Herbst 1941 im Vergleich zum Vorjahr die Zahl der Interessenten in Saloniki derartig anstieg, daß viele Bewerber trotz großzügiger Auslegung der Kapazitäten des Lektorates abgewiesen werden mußten. Im Herbst 1942 verdoppelte sich die Hörerschaft im Vergleich zum Vorjahr dann nochmals auf 2400.78

Geographisch blieb die Arbeit der Deutschen Akademie auf einen Teil des vom Reich beherrschten Europas beschränkt. Dies war nicht nur Folge des Mangels an geeigneten Lehrkräften seit Ende 1941, sondern vielmehr eine bewußte politische Entscheidung. Die Tätigkeit der Deutschen Akademie, die im Selbstverständnis der Machthaber des Dritten Reiches ein Instrument der Auslandskulturpolitik war und bleiben sollte, endete dort, wo auch der Einfluß des Auswärtigen Amts bei der Formulierung der Reichspolitik gegenüber den jeweiligen unterworfenen Staaten seine Grenzen fand. Folglich gab es keine Lektorate im besetzten Polen, den eroberten Gebieten der Sowjetunion oder im „Protektorat Böhmen und Mähren“. Das Schicksal der Teilgebiete des 1939 zerschlagenen tschechoslowakischen Staates liefert dafür ein bezeichnendes Beispiel: Im formal seit März 1939 selbständigen Rumpfstaat Slowakei wurde die Akademie ab 1940 aktiv. Im „Protektorat“ hingegen, dessen Bevölkerung zum überwiegenden Teil „germanisiert“,

77 BAB R51/12, Protokoll der Mitarbeiterbesprechung in Salzburg, 10. 11. 1944.

78 Vgl. Michels, Das Deutsche Institut, S. 188-218. Zu Griechenland siehe Hagen Fleischer, Europas Rückkehr nach Europa. Kulturpolitik der Großmächte in einem Staat der Peripherie, in: Die Griechen und Europa. Außen- und Innenansichten im Wandel der Zeit, hrsg. von Harald Heppner und Olga Katsiardi-Hering, Köln u.a. 1998, S. 125-191, hier S. $157-160$. 
während die als nicht „assimilierungsfähig“ angesehenen Teile später vertrieben werden sollten, wurde ihr eine entsprechende Tätigkeit verwehrt unter dem Hinweis, eine Arbeit hier würde andernfalls zu einer staatsrechtlichen Aufwertung des Territoriums führen. ${ }^{79}$ Die Deutsche Akademie sollte also nur in jenen Ländern tätig sein, deren Bevölkerung gemäß den rassischen Kriterien des Nationalsozialismus für Wert befunden worden war, an der deutschen Sprache und Kultur teilzuhaben und die ein Mindestmaß an Selbständigkeit in einem "neuen Europa“ behalten würden. Zudem wäre es in der perversen Logik der Nationalsozialisten auch widersinnig gewesen, Kulturwerbung unter Völkern zu betreiben, deren Schicksal nach einem deutschen „Endsieg“ vermutlich die rücksichtslose Vertreibung mit der bewußten Inkaufnahme millionenfachen Todes unter den Entwurzelten gewesen wäre, wie es z.B. seit 1941 in den Heinrich Himmler unterstehenden Dienststellen im „Generalplan Ost“ vorgesehen wurde. ${ }^{80}$

Das Propagandaministerium, das die Propagandakompetenz von Rosenbergs im Sommer 1941 geschaffenen „Ostministerium“ für die eroberten Gebiete der UdSSR bestritt, wollte im Juni 1942 Mittelstellen der Deutschen Akademie im Baltikum einrichten lassen. Bei den entsprechenden Gesprächen in Berlin wies der Vertreter der Deutschen Akademie nicht nur auf den seit längerer Zeit herrschenden Lektorenmangel hin, der die Errichtung von Außenstellen im Baltikum erschweren würde. Die anderen Behörden machten ferner darauf aufmerksam, daß das Baltikum „Inland“ sei, und somit, wenn überhaupt, nur die „Deutsche Arbeitsfront" dort Sprachkurse veranstalten solle. Schließlich wurde auch auf Rosenbergs „Spracherlaß“ vom 29. Juli 1941 verwiesen, der ein fein abgestuftes System vorsah, dem man entnehmen konnte, welche der "Ostvölker“ in welchem Umfang Deutsch lernen sollten und dürften: Bei den baltischen Völkern, die als weitgehend assimilierungsfähig angesehen wurden, seien weit verbreitete Deutschkenntnisse durchaus erwünscht, Weißrussen dürften immerhin Deutsch lernen, bei Ukrainern und Großrussen sei dies hingegen unerwünscht. Diese Regelung sei sinngemäß auch auf die „Fremdarbeiter“ der jeweiligen Nationalitäten im Reich anzuwenden. ${ }^{81}$

Erst im Frühjahr 1944 schien es für einen Moment so, als würde sich auch im Osten ein Tätigkeitsfeld für die Spracharbeit der Akademie eröffnen. Im April kam es zu Verhandlungen in Krakau zwischen Nitschke und den Behörden des Generalgouvernements über die Einrichtungen von Lektoraten auf polnischem Boden. Doch ging es dabei weniger darum, den Polen Zugang zur deutschen Sprache zu ermöglichen, als um eine rein kosmetische Operation. Indem man die Aka-

79 Scholten, Sprachverbreitungspolitik des nationalsozialistischen Deutschlands, S. $186 \mathrm{f}$.

80 Zum Generalplan Ost vgl. Mechthild Rösler und Sabine Schleiermacher (Hrsg.), Der Generalplan Ost. Hauptlinien der nationalsozialistischen Planungs- und Vernichtungspolitik, Berlin 1993.

81 BAB R51/34, Bericht über die Besprechungen in Berlin in der Frage der Spracharbeit in den besetzten Ostländern vom 8.-10. 6. 1942. Zu Rosenbergs Spracherlaß vgl. auch Alexander Dallin, Deutsche Herrschaft in Rußland 1941-1945. Eine Studie über Besatzungspolitik, Düsseldorf 1958, S. 480 f. Vgl. zum abgestuften System des Zugangs zur deutschen Sprache in den eroberten Gebieten der UdSSR jetzt auch Scholten, Sprachverbreitungspolitik des nationalsozialistischen Deutschlands, S. $247 \mathrm{ff}$. 
demie ins Generalgouvernement holte, sollte der Eindruck einer nunmehr liberaleren Polenpolitik erweckt werden und das Generalgouvernement gleichsam von einem Kolonialgebiet zu einem mehr oder minder "normalen“ Besatzungsland aufgewertet werden. Die Initiative war Bestandteil der schon seit längerem unternommenen Versuche von Generalgouverneur Hans Frank, eine zumindest nach außen hin humaner erscheinende Polenpolitik einzuführen, um die Verwaltung des Landes zu erleichtern und es für die deutschen Kriegsanstrengungen effektiver in den Dienst nehmen zu können. ${ }^{82} \mathrm{Da}$ aber alle ernsthaften Konzessionen an die Polen seit 1943 am Widerstand Heinrich Himmlers und Hitlers gescheitert waren, erhoffte man sich in Krakau wenigstens durch solch symbolische Akte eine Klimaverbesserung. Nitschke berichtete denn auch nach seiner Dienstreise nach Krakau:

„Die Regierung des Generalgouvernements will - so wurde unmißverständlich zum Ausdruck gebracht - eine neue Polenpolitik durchführen. Man will die Deutsche Akademie als Fassade verwenden und der Weltöffentlichkeit und den Polen gegenüber durch Gründung von Akademielektoraten zeigen, daß die Polen wie andere Völker behandelt werden sollen. Ein Kulturaustausch komme zunächst für das Generalgouvernement nicht in Frage."

Das Ganze sei laut Äußerungen seiner Gesprächspartner ein „taktisches Manöver, für das die Deutsche Akademie benötigt werde“. Der Ausdruck „Fassade“ sei in den Besprechungen mehrmals gefallen. ${ }^{83}$ Die Versuche der Akademie, 1939 zunächst im „Protektorat Böhmen und Mähren“, 1942 im Baltikum und 1944 schließlich im Generalgouvernement mit Lektoraten Fuß zu fassen, zeigen, daß man sich in München nicht unbedingt um die feinen Abstufungen der Souveränität oder kulturellen Selbstbestimmung kümmerte, die das NS-Regime den unterworfenen Völkern in Abhängigkeit von der ihnen zugeschriebenen „rassischen Wertigkeit" zudachte. Man akzeptierte sie zwar und war auch bereit, sich widerspruchslos als „Fassade“ für eine sich „liberaler“ gebende Besatzungspolitik mißbrauchen zu lassen. Doch scheint in München das vorrangige Ziel gewesen zu sein, an möglichst vielen Stellen Europas präsent zu sein, um den selbstgestellten Auftrag „Weltsprache Deutsch“ zu erfüllen und damit den weiteren Ausbau der Akademie auch in Kriegszeiten sicherzustellen, ohne den rassistischen Kriterien zu viel Beachtung zu schenken.

Die Deutsche Akademie war auch nicht in den besetzten "germanischen“ Ländern Norwegen und den Niederlanden aktiv, wo sie nur Büros als Verbindungsstellen besaß, aber praktisch keine Spracharbeit betrieb außer mit einem einzigen Lektor in Oslo. In diesen beiden Ländern glaubte man die deutsche Sprache im Zuge einer späteren Annexion, die sich bereits durch die Verwaltung dieser Länder durch zivile deutsche Reichskommissare abzeichnete, ${ }^{84}$ mit anderen Mitteln

82 Hans Umbreit, Die deutsche Herrschaft in den besetzten Gebieten 1942-1945, in: Das Deutsche Reich und der Zweite Weltkrieg. Bd. 5/2 Kriegsverwaltung, Wirtschaft und personelle Ressourcen 1942-1944/45, hrsg. vom Militärgeschichtlichen Forschungsamt, Stuttgart 1999, S. 3-274, hier S. 11 f. und $56 \mathrm{ff}$.

$83 \mathrm{BAB}$ R51/34, Bericht über die Dienstreise des Abteilungsleiters Dr. Nitschke zu Dienstbesprechungen in Krakau, 19.-23. 4. 1944.

84 Zur Frage, inwieweit die Form der Besatzungsherrschaft als Indiz für die weitergehenden Pläne des NS-Regimes für die betroffenen Länder dienen kann, vgl. Hans Umbreit, Die 
durchsetzen zu können, vor allem durch frühen zwangsweisen Unterricht in den Schulen. In den beiden Reichskommissariaten war es daher in den Augen des NSRegimes nicht angebracht, Deutsch als Fremdsprache in größerem Ausmaß durch eine Einrichtung der Auslandskulturpolitik zu lehren. Selbst als Ende $1943 \mathrm{mit}$ Arthur Seyß-Inquart der Reichskommissar der besetzten Niederlande Präsident der Akademie wurde, kam es im Anschluß daran nicht zur Vergrößerung des Akademie-Büros in Den Haag, geschweige denn zur Aufnahme der Spracharbeit in Holland. Vermutlich wäre es nach einem Endsieg eher zu einer Zwangsgermanisierung gekommen, in der man Norwegisch und Niederländisch als germanische "Dialekte“ zugunsten des Deutschen unterdrückt hätte. Dafür spricht die sprachpolitische Vorgehensweise in dem seit 1940 de facto annektierten, als „germanisch" angesehenen Luxemburg und in Elsaß-Lothringen. Hier war nicht etwa Zweisprachigkeit das Ziel, sondern die vollkommene Verdrängung des Französischen (im Falle Luxemburgs ab 1942 auch des dem Deutschen verwandten Letzeburgischen) durch das Deutsche mittels Verboten und Strafandrohung. ${ }^{85}$

Als weitere Beispiele, welche die Grundsätze verdeutlichen, auf denen die Dislozierungspolitik der Deutschen Akademie basierte, mögen Dänemark und Belgien dienen. Beides waren Länder mit „germanischer" Bevölkerung oder zumindest Bevölkerungsteilen, denen diese Eigenschaft zugeschrieben und die als „eindeutschungsfähig" erachtet wurden. Ihre Zukunft sollte aber wegen der Umstände ihrer Besetzung oder des vom weiteren Verlauf des Krieges abhängenden Schicksals noch nicht durch eine zu offenkundige, annexionsartige Form der Besatzungsherrschaft präjudiziert werden. In beiden Ländern war die Deutsche Akademie daher seit 1940 aktiv. ${ }^{86}$ Dabei sollte sie im Falle Belgiens auf Wunsch Himmlers in seiner Eigenschaft als sogenannter Reichskommissar für die Festigung des deutschen Volkstums ihre Aktivitäten besonders in den ohnehin als "germanisch" angesehenen Gebieten Flanderns intensivieren, um hier eine Germanisierung ungeachtet späterer friedensvertraglicher Regelungen schon unter der Hand vorwegzunehmen. Auch dies scheiterte allerdings am Personalmangel. 87

Im übrigen war die Verbreitung der deutschen Sprache im Ausland, wie sie die Deutsche Akademie betrieb, auch eine zweischneidige Sache, nimmt man die damals in Deutschland vorherrschende Auffassung von Sinn und Zweck des Fremdsprachenunterrichts für bare Münze. Seit Mitte der zwanziger Jahre hatte sich im Fremdsprachenunterricht und in der Philologie das Konzept der „neuen“ Kulturkunde durchgesetzt, d.h. alle geistigen Äußerungen und materiellen Leistungen

deutschen Besatzungsverwaltungen: Konzept und Typisierung, in: Der Zweite Weltkrieg. Grundzüge, Analysen, Forschungsbilanz, hrsg. von Wolfgang Michalka, München 1989, S. 710-725.

85 Polenz, Deutsche Sprachgeschichte, Bd. 3, S. 150 ff. Für Luxemburg jetzt auch Scholten, Sprachverbreitungspolitik des nationalsozialistischen Deutschlands, S. $119 \mathrm{ff}$.

86 Das gleiche Muster der geographischen Verteilung läßt sich bei den Deutschen Wissenschaftlichen Instituten erkennen. Vgl. Eckard Michels, Die deutschen Kulturinstitute im besetzten Europa, in: Kultur - Propaganda - Öffentlichkeit, hrsg. von Wolfgang Benz u.a., Berlin 1998, S. 11-33.

87 Einige Schriftstücke hierzu befinden sich in: BAB R51/34. 
eines Volkes wurden nun im Sinne einer einheitlichen Deutung des fremden Volkscharakters zusammengefaßt. Die so pauschalisierte fremde Kultur sollte wiederum als Folie dienen, um die eigene Sprache und Kultur um so besser erkennen zu können. ${ }^{8}$ Diese Deutung vom Sinn kultureller Begegnung, beim DAAD seit Anfang der dreißiger Jahre sogar zum Leitmotiv der Auslandsarbeit erhoben, blieb auch im Dritten Reich dominierend. So bestimmte das RMEWV in einem 1938 verabschiedeten neuen Lehrplan, daß das Ziel des Fremdsprachenunterrichts nicht nur die Erlernung des praktischen Gebrauchs einer Fremdsprache sowie die formale geistige Bildung sei. Vielmehr hieß es in diesem Lehrplan auch, „durch Vergleich der Fremdsprache mit der Muttersprache, des fremden Wesens mit dem deutschen Wesen trägt der neusprachliche Unterricht dazu bei, daß sich der Schüler der Eigenart und des Wertes des eigenen Volkes und seiner arteigenen Kultur stärker bewußt wird". ${ }^{89}$ Auf das Ausland angewendet, implizierte diese Auffassung vom Sinn und Zweck der Erlernung von Fremdsprachen und der Begegnung mit einer fremden Kultur, daß der Hörer eines Deutschkurses der Deutschen Akademie in Frankreich, Bulgarien oder Portugal nicht nur die deutsche Sprache und Kultur vermittelt bekäme, sondern letztlich der Unterricht ihn zu einem noch (selbst- )bewußteren Franzosen, Bulgaren oder Portugiesen formte. Auch unter diesem Gesichtspunkt machte die Beschränkung der Spracharbeit der Deutschen Akademie auf Länder Sinn, die für die Germanisierung als ungeeignet galten, denen aber ein Mindestmaß von Unabhängigkeit und kultureller Selbstbehauptung auch im "neuen Europa" zugedacht war. In den erhaltenen Dokumenten und Publikationen der Deutschen Akademie ist dieses zumindest theoretische Dilemma zwischen dem Anspruch der Arbeit der Akademie einerseits, also Deutschland als führende kulturelle Macht auf dem Kontinent zu präsentieren, und der möglichen Wirkung bei den unterworfenen Völkern im Sinne einer durch die Begegnung mit der deutschen Sprache erfolgenden Sensibilisierung für ihre eigenen kulturellen Wurzeln andererseits, allerdings nie thematisiert worden. Es sei dahingestellt, inwieweit diese Auffassung auch dazu beigetragen hat, bestimmte Länder im Osten Europas oder die „germanischen“ Brudernationen Norwegen und die Niederlande nicht mit Lektoraten zu versehen, um nicht unbeabsichtigt dazu beizutragen, ihnen ihre kulturellen Wurzeln um so bewußter zu machen.

Abgesehen davon, daß die Rassedoktrin der Nationalsozialisten an sich schon eine Germanisierung der meisten unterworfenen Völker in Form einer Oktroyierung der deutschen Sprache wegen ihrer angenommenen genetischen Andersartigkeit ausschloß, da es laut Hitlers „Mein Kampf“ nur eine „Germanisierung des Bodens“, nicht des Menschen geben könne, ${ }^{90}$ war die Dominanz der „neuen Kul-

88 Gerhard Bott, Deutsche Frankreichkunde 1900-1933. Bd. 1, Rheinfelden 1982, S. 93 ff.

89 Zitiert nach Magda Gerken, Aufgaben des neusprachlichen Unterrichts. Gedanken zu dem neuen deutschen Lehrplan für höhere Schulen, in: Deutschunterricht im Ausland, Heft 1 (1941), S. 1-4, hier S. 1.

90 So wandte sich Hitler schon in den zwanziger Jahren gegen die seiner Auffassung nach fälschliche, aber selbst in alldeutschen Kreisen vertretene Ansicht, daß durch Sprachverbreitung eine Germanisierung des Slawentums in der Habsburgermonarchie möglich gewesen wäre. „Da das Volkstum, besser die Rasse, eben nicht in der Sprache liegt, sondern im Blute, würde man von einer Germanisation erst dann sprechen dürfen, wenn es ge- 
turkunde" im Fremdsprachenunterricht des Dritten Reiches jedenfalls ein weiterer Grund dafür, daß die Auslandsarbeit der Deutschen Akademie von ihrem Selbstverständnis her niemals in eine Germanisierungsmission ausufern konnte. Gerade weil die Deutsche Akademie bis 1945 ein Instrument blieb, das nur in Ländern tätig war, die nach dem Willen der Führung des Reichs trotz deutscher Hegemoniepolitik als mehr oder weniger selbständige Staaten weiterbestehen sollten, degenerierte sie nicht zu einem Instrument einer zwangsweisen Germanisierung, wie sie z.B. vom NS-Regime rücksichtslos in Luxemburg, Elsaß-Lothringen oder den annektierten Teilen Polens verfolgt wurde. Sie betrieb auch keinen Kulturimperialismus in dem Sinne, daß sie die Kultur der Gastvölker durch die deutsche verdrängen wollte; allenfalls dahingehend, daß sie kulturelle Einflüsse von Drittstaaten zurückzudrängen versuchte. So erklärte ihr Präsident denn auch intern auf der Mittelstellenleitertagung 1944: „Wir gehen nicht hinaus, um Gastvölkern unser Wissen aufzuzwingen, wir müssen Völker so nehmen wie sie sind, Fragen stellen: Was wollen die Völker von uns, was können wir ihnen aus unserem Kulturgut geben." ${ }^{\text {91 }}$

\section{Von Siebert zu Seyß-Inquart}

Am 1. November 1942 starb Siebert achtundsechzigjährig. Einige Wochen später ereilte das gleiche Schicksal den zweiten Vizepräsidenten von Stauß, der sich bei Sieberts Beerdigung eine schwere Erkältung zugezogen hatte. Bevor es zur Ernennung des Nachfolgers für Siebert kam - von Stauß' Funktion war rein repräsentativ gewesen und wurde daher nicht mehr neu besetzt -, schickte das Propagandaministerium im Februar 1943 einen neuen Generalsekretär, den Oberregierungsrat Matthias Schmitz. Der Posten des Generalsekretärs war seit Fochler-Haukes endgültigem Entschluß im Mai 1941, die militärische Karriere vorerst der wissenschaftlichen vorzuziehen, vakant, obwohl er in der Gehaltsliste der Akademie bis Anfang 1943 weiter als Generalsekretär geführt wurde. Offenbar war Siebert sehr an diesem Mitarbeiter gelegen. Als sich im Frühjahr 1941 abzeichnete, daß Fochler-Hauke erneut zur Wehrmacht einrücken wollte, erwog Siebert sogar kurzzeitig, für diese Aufgabe Thierfelder zu reaktivieren, der zu Fragen der Auslandskulturpolitik weiterhin publizistisch sehr aktiv war. ${ }^{92}$ Die Initiative scheiterte aber vor allem am Einspruch von Wüst. Den Posten bekleidete folglich zunächst kommissarisch Sieberts Sohn Fritz, ein bayerischer Beamter, und, nachdem dieser im Januar 1942 nach Krakau in die Verwaltung des Generalgouvernements versetzt

länge, durch einen solchen Prozeß das Blut der Unterlegenen umzuwandeln. Das aber ist unmöglich. "In: Hitler, Mein Kampf, S. 428. In einem seiner nächtlichen Monologe verstieg sich Hitler sogar dazu zu behaupten, die Eßgewohnheiten seien ein wichtigeres Kennzeichen für die Zusammengehörigkeit eines Volkes als die Sprache. Jochmann, Monologe im Führerhauptquartier, 11./12. 7. 1941 (S. 41).

91 BAB R51/26, Protokoll der Tagung der Mittelstellenleiter, 11.-16. 2. 1944.

92 Einige Schriftstücke hierzu befinden sich in: BAB R51/10144. 
worden war, der im März 1942 neu eingestellte Verwaltungsdirektor Joseph Heitzer.

Der neue Generalsekretär Schmitz sollte offenbar das Terrain für den von Hitler laut $₫ 3$ des „Führererlasses“ zu ernennenden zukünftigen Präsidenten sondieren. Der 1899 in Duisburg geborene Schmitz hatte Germanistik, Geschichte und Pädagogik studiert. Er war 1926 in die USA gegangen, um in Harvard zu promovieren. Seit 1936 in der NSDAP, leitete er bis kurz vor dem Kriegseintritt der USA die dem Propagandaministerium unterstehende "Deutsche Informationsbibliothek" in New York. Seit 1941 arbeitete er in der Auslandsabteilung des GoebbelsMinisteriums. Seit seinem Dienstantritt in München schmückte er sich mit einem Professorentitel, ohne aber jemals habilitiert oder einen Lehrstuhl bekleidet zu haben. Er blieb bis Kriegsende Generalsekretär. ${ }^{93}$ Mit der Entsendung von Schmitz wollte das Propagandaministerium zugleich unterstreichen, daß es nicht gewillt war, dem Auswärtigen Amt Einfluß in der Geschäftsstelle der Akademie in München einzuräumen. Denn die Frage des vakanten Präsidentenpostens brachte erneut die Wilhelmstraße auf den Plan. Bei der Suche nach einem Nachfolger für Siebert bemühte sich das Auswärtige Amt, einen nach außen hin politisch neutral erscheinenden Kandidaten ins Rennen zu schicken. In der Wilhelmstraße dachte man entweder an einen Wissenschaftler, der für die wissenschaftliche Seriosität des Unternehmens bürgen konnte, oder an einen Schriftsteller als führenden Vertreter der deutschen Sprache. Damit wollte man nicht nur die angeblich unpolitische Seite der deutschen Kulturwerbung im Ausland herausstreichen, eine aus der Weimarer Republik ererbte Tradition, die zu diesem Zeitpunkt im Auswärtigen Amt noch durch von Weizsäcker und von Twardowski, dem Leiter der Kulturpolitischen Abteilung, schwach fortlebte. ${ }^{94}$ Dies war aber wohl eher ein in den Erwägungen des Auswärtigen Amts nachgeordnetes Motiv, das allerdings als vorgeschobenes Argument diente. Der Anspruch einer „unpolitischen“ Kulturwerbung zum Ausland durch anscheinend staatsferne Institutionen war im Falle der Münchener Einrichtung spätestens seit der auch von der Wilhelmstraße unterstützten Ernennung Sieberts und der Erhebung der Akademie zu einer Körperschaft des Öffentlichen Rechts mit einem von Hitler zu ernennenden Präsidenten unglaubwürdig. Entscheidender war wohl eher der Wunsch der Wilhelmstraße, dadurch zu verhindern, daß das Propagandaministerium einen seiner eigenen Beamten an die Spitze der Akademie stellen würde. Goebbels erwog, entweder Ministerialdirektor Heinrich Hunke oder Staatssekretär Leopold Gutterer Hitler als Nachfolger vorzuschlagen, was das Auswärtige Amt noch weiter aus den Geschicken der Akademie herausgedrängt hätte. Allerdings blieb das Auswärtige Amt chancenlos mit seinen Vorschlägen. Die starke Abneigung Hitlers gegen das Auswärtige Amt

93 Angaben zu Schmitz in seinen Personalunterlagen im Berlin Document Center des Bundesarchivs sowie in: BAB R51/10143.

$94 \mathrm{BAB}$ R/II/1232a, Schreiben von Weizsäckers an Lammers, 31. 12. 1942. Beide verloren im März 1943 im Zuge eines personalpolitischen Revirements im Auswärtigen Amt ihre Posten. Die Leitung der Kulturpolitischen Abteilung übernahm der SS-Führer, Dekan der Auslandswissenschaftlichen Fakultät der Berliner Universität und diplomatische Seiteneinsteiger Franz Alfred Six. 
- schon in den dreißiger Jahren hatte er die Diplomaten als „Weihnachtsmänner in der Wilhelmstraße" tituliert ${ }^{95}$, geht deutlich aus einem Vermerk Lammers' hervor. Als dieser Hitler Vortrag über die von den beiden Ministerien ins Spiel gebrachten Anwärter auf das Präsidentenamt hielt und dabei auch die vom Auswärtigen Amt favorisierten Kandidaten, den Historiker und Präsidenten der Bayerischen Akademie der Wissenschaften Karl Alexander von Müller und den Schriftsteller und Präsidenten der Reichsschrifttumskammer Hanns Johst, erwähnte, scheint Hitler geradezu gereizt reagiert zu haben, denn Lammers notierte: „Der Führer erklärte mir hierzu, daß das Auswärtige Amt an der Frage der Besetzung der Präsidentenstelle überhaupt nicht zu beteiligen sei und hierbei nicht im geringsten mitzuwirken habe; die Besetzung der Präsidentenstelle gehe das Auswärtige Amt gar nichts an. Er wünscht, daß es in dieser Angelegenheit völlig ausgeschaltet werde." $" 96$

Nun war es also ganz an Goebbels, einen geeigneten Kandidaten zu bestimmen. Die gesuchte Person sollte ein gewisses internationales Renommee haben, was letztlich gegen einen Staatssekretär aus dem eigenen Hause sprach, gleichzeitig aber nicht zu unabhängig agieren, sondern den Vorstellungen des Propagandaministeriums folgen. ${ }^{97}$ Goebbels' Vorschlag, einen seiner Staatssekretäre zum Präsidenten zu küren, scheiterte zudem am Widerstand der Parteikanzlei, die ebenfalls negative Rückwirkungen auf das Ausland fürchtete und Goebbels auch nicht mehr Einfluß als nötig zugestehen wollte. Daraufhin brachte Goebbels bei Hitler im März 1943 verschiedene Kandidaten ins Spiel: Den Bildhauer Arno Breker, den Leiter der „Kanzlei des Führers“ Philipp Bouhler, Ex-Außenminister von Neurath und die Industriellen Alfried Krupp von Bohlen und Halbach und Albert Vögler. Im März 1943 schien die Wahl zunächst auf den von Goebbels favorisierten und wohl auch Hitler genehmen Breker zu fallen. ${ }^{98}$ Doch offenbar winkte dieser ab, denn Anfang Mai 1943 stimmte Hitler laut Goebbels' Tagebuch doch dem Vorschlag des Propagandaministeriums zu, Vögler zu ernennen, der in den dreißiger Jahren zwischenzeitlich als Vertreter des Wirtschaftrates im Kleinen Rat der Akademie gesessen hatte. ${ }^{99}$ Allerdings schlug auch dieser - er stand seit 1940 bereits der Kaiser-Wilhelm-Gesellschaft der Wissenschaften vor -, das Angebot nach einigen Monaten der Überlegung aus. Im Herbst 1943 brachte Goebbels schließlich Arthur Seyß-Inquart, den Reichskommissar der besetzten Niederlande und seit 1939 zugleich Reichsminister ohne Geschäftsbereich, als Nachfolger Sieberts ins Spiel. „Sehr einverstanden ist der Führer mit meinem Vorschlag, Reichsminister Seyß-Inquart zum Präsidenten der Deutschen Akademie zu machen. Ich glaube, es wäre die beste Lösung. Der Posten muß besetzt werden, und

$95 \mathrm{Vgl}$. Döscher, Das Auswärtige Amt im Dritten Reich, S. $85 \mathrm{ff}$.

96 BAB R43/II/1232a, Vermerk betr. Ernennung eines neuen Präsidenten der Deutschen Akademie, 26. 1. 1943.

97 Vgl. die vom Propagandaministerium unmittelbar nach Sieberts Tod ventilierten Vorschläge, in: BAB R55/177, Vorschläge für die Präsidentschaft der Deutschen Akademie, Aufzeichnung vom 4. 11. 1942.

98 Die Tagebücher von Joseph Goebbels Teil 2, Bd. 7, S. 509 (Eintragung vom 9. 3. 1943).

99 Die Tagebücher von Joseph Goebbels Teil 2, Bd. 8, S. 263 (Eintragung vom 10. 5. 1943). 
Seyß-Inquart ist immerhin ein Mann von internationalem Ruf und großem Format", notierte Goebbels am 27. Oktober in seinem Tagebuch. ${ }^{100}$

Goebbels' Wahl wirkt auf den ersten Blick erstaunlich und war sicherlich zu einem guten Teil eine Verlegenheitslösung in einer Frage, die ihm angesichts der katastrophalen Meldungen von der Ostfront, aus Nordafrika und Italien, die zwischen Frühjahr und Herbst 1943 in Berlin eintrafen und entsprechende Rückwirkungen auf die Stimmung im Reich hatten, nicht sonderlich dringlich erschien. Zwar war der gebürtige Österreicher Seyß-Inquart seit 1938 Ehrenmitglied der Deutschen Akademie, hatte aber ansonsten keine engen Bindungen zu der Münchener Institution aufgebaut oder besonderes Interesse für ihre Arbeit bewiesen. Er besaß weder den Stallgeruch des Propagandaministeriums, noch hatte er sich einen Namen als Wissenschaftler oder Literat gemacht. Allerdings verfügte der promovierte Jurist zweifellos über ein größeres intellektuelles Format als die meisten anderen hohen NS-Funktionäre. Er hielt sich selbst für einen „kultivierten Menschen" und Förderer der Künste, was sich u.a. darin niederschlug, daß er deutsche Orchester in die besetzten Niederlande einlud, dort „Wiener Kunstwochen" veranstalten ließ und sich Anfang 1942 persönlich bei Goebbels dafür einsetzte, in Den Haag ein deutsches Theater eröffnen zu dürfen. ${ }^{101}$

Die Kür eines führenden deutschen Besatzungspolitikers und Reichsministers war eine Art Affront gegen das Auswärtige Amt, das ja vergeblich versucht hatte, einen zumindest nach außen hin von den Schalthebeln der Macht entfernten Kandidaten zum Präsidenten der Akademie zu berufen. Folgt man Goebbels' Tagebucheinträgen, so „entdeckte“ er Seyß-Inquart im Frühjahr 1943 zunächst als potentiellen Verbündeten in seinem Kampf für eine Intensivierung der deutschen Kriegsanstrengungen, die er in seiner berühmten Sportpalastrede im Februar 1943 angekündigt hatte. So notierte der am 6. März 1943 in seinem Tagebuch: „Ich habe eine sehr ausgedehnte Aussprache mit Seyß-Inquart über den totalen Krieg [...] Ich stelle hier eine absolute Übereinstimmung unserer Ansichten fest. Seyß-Inquart ist ein kluger politischer Kopf, der in der österreichischen Schule großgeworden ist." Am 8. September 1943 heißt es schließlich hinsichtlich Seyß-Inquarts Politik in den besetzten Niederlanden: „Seyß-Inquart versteht es meisterhaft, mit Zuckerbrot und Peitsche abzuwechseln und harte Maßnahmen mit einer großen Elastizität durchzuführen. Man merkt ihm die gute Habsburger Schule an [...] Dabei haben sie (die Österreicher, E.M.) sich eine große Übung in der Behandlung von Völkern auch in kritischen Situationen erworben. "102 Elastizität und Härte schienen Eigenschaften zu sein, die auch bei der Führung der vor allem auf das Ausland zielenden Deutschen Akademie gefragt waren. Ausschlaggebend aber war für Goebbels' Personalentscheidung vermutlich der Faktor, daß Seyß-Inquart als Österreicher und praktizierender Katholik weder in der Partei eine starke Hausmacht hatte, ${ }^{103}$ noch enge Bindungen zum Auswärtigen Amt besaß. Er stand vielmehr als direkt Hitler unterstehender Reichskommissar eines besetzten Lan-

100 Die Tagebücher von Joseph Goebbels Teil 2, Bd. 10, S. 190.

101 Hendricus Johannes Neuman, Arthur Seyß-Inquart, Wien u. a. 1970, S. 257 ff.

102 Die Tagebücher von Joseph Goebbels Teil 2, Bd. 9, S. 447.

103 Neumann, Seyß-Inquart, S. 168-170. 
des in einer gewissen Konkurrenz zur Wilhelmstraße. Zugleich konnte Goebbels auf Hitlers Zustimmung rechnen, denn Seyß-Inquart genoß bei seinem Landsmann wegen seiner angeblich geschickten Amtsführung in den Niederlanden hohes Ansehen. Dieses fand schließlich 1945 seinen deutlichsten Ausdruck darin, daß Hitler Seyß-Inquart in seinem Testament zum Außenminister ernannte. Mithin hatte Goebbels also in ihm einen Kandidaten gefunden, der nach außen hin ein gewisses Renommee und als Österreicher und Reichskommissar der besetzten Niederlande einen gewissen, wenn auch fraglichen internationalen Hintergrund hatte. Er war für Hitler wie für die Parteikanzlei akzeptabel - auf das Auswärtige Amt brauchte zu diesem Zeitpunkt ohnehin keine Rücksicht mehr genommen zu werden -, und war zugleich auf enge Zusammenarbeit mit dem Propagandaministerium angewiesen, dem er hinsichtlich einer Intensivierung der Kriegsanstrengungen ohnehin grundsätzlich zustimmte.

Anfang Dezember 1943 akzeptierte Seyß-Inquart den ihm angetragenen Posten. Das Propagandaministerium steckte mit Seyß-Inquart vor der offiziellen Amtseinführung den zukünftigen Kurs für die Deutsche Akademie ab. Die Geltung der Akademie im Inland sollte durch Wiederbelebung der Forschung verstärkt werden, allerdings dahingehend, daß man eher bestehende Forschungsergebnisse komprimiert und repräsentativ der Öffentlichkeit zugänglich machen wollte, als eigene zu betreiben, da letzteres nur Konflikte mit bestehenden Institutionen heraufbeschwören würde. Die im „Führererlaß“ postulierte Aufgabe der Sprachpflege im Inland sollte nun endlich in München begonnen werden, wozu die Akademie ein eigenes „Sprachamt" erhalten würde. Die Auslandsarbeit müsse stärker als bisher um „kulturelle Aufklärungstätigkeit“ ergänzt werden, sonst würden die Lektorate zu bloßen Sprachschulen herabsinken. Seyß-Inquart und der für die Akademie zuständige Referent des Propagandaministeriums, Ministerialrat Wilhelm Ziegler, kamen überein, daß die Deutsche Akademie langfristig Träger der wissenschaftlichen Beziehungen zum Ausland werden und damit die Deutschen Wissenschaftlichen Institute ersetzen solle. ${ }^{104}$ Anscheinend köderte man Seyß-Inquart nicht nur mit einer zukünftig über die Sprachförderung hinausgehenden Aufgabenstellung der Akademie, sondern auch mit einem nochmals erweiterten Haushalt, denn dieser sah für 1944 eine Verstärkung der Zahl der Inlandsmitarbeiter vor: Die wissenschaftliche Abteilung sollte von fünf auf $31 \mathrm{Mit}-$ arbeiter aufgestockt werden, das Goethe-Institut von neun auf 24 Mitarbeiter anwachsen, und der Abteilung Auslandslektorate unter Nitschke würden statt bislang elf zukünftig 21 Stellen zustehen, davon neun Referenten. Selbst für das Verbindungsbüro der Akademie in Berlin war eine Verdoppelung der Mitarbeiterzahl von vier auf acht beabsichtigt. Für den Mitarbeiterstab im Inland waren nun insgesamt 129 Planstellen vorgesehen. ${ }^{105}$ Die Gesamtzahl der Mitarbeiter der Deutschen Akademie, inklusive der etwa 180 entsandten Lektoren und der Ortskräfte im Ausland, belief sich damit im Frühjahr 1944 auf rund 1000 Personen.

104 BAB R55/177, Aufzeichnung Zieglers für Goebbels über sein Gespräch mit Seyß-Inquart in Den Haag, 7. 1. 1944.

105 BAB R2/4780, Haushaltsvoranschlag der Deutschen Akademie 1944. 
Am 10. Februar 1944 führte Goebbels schließlich in einer Feierstunde in der Aula der Münchener Universität Seyß-Inquart in sein neues Amt ein. Es sollte die erste und zugleich letzte aufwendige, öffentliche Ernennungszeremonie für einen Präsidenten der Deutschen Akademie sein. Goebbels legte der Deutschen Akademie in einer kurzen Ansprache die Pflege und Verbreitung der deutschen Sprache ans Herz, vor allem in Zeiten des Krieges. Er bezeichnete die Sprache "als scharf geschliffenes Schwert zur geistigen Verteidigung einer Nation“. Schon an der Niederringung Napoleons hätten wenige so viel Anteil gehabt wie der „General der deutschen Sprache" Johann Gottlieb Fichte. Seyß-Inquart war in seiner Rede präziser hinsichtlich des zukünftigen Kurses der Deutschen Akademie. Seine Ausführungen deckten sich mit den im vorhinein mit dem Propagandaministerium abgesprochenen Direktiven: Die wissenschaftliche Abteilung solle eher bestehende Ergebnisse zusammenfassen und bei ihren Publikationen stets die kulturellen Einflüsse Deutschlands auf das Ausland im Auge behalten. In der Sprachwerbung werde es künftig mehr Spezialkurse für Ärzte, Juristen und Techniker geben und insgesamt der Nachdruck stärker auf Kurse für Fortgeschrittene gelegt werden, denen man auch mehr deutsche Kultur vermitteln könne. Die Vermittlung von Grundkenntnissen in der deutschen Sprache für die breite Masse könne nicht Aufgabe der Deutschen Akademie sein und solle daher speziellen Sprachschulen überlassen oder ștärker als bisher den Schulen der fremden Länder zur Aufgabe gemacht werden. Die Lektorate der Deutschen Akademie sollten sich hingegen zukünftig mehr dem Deutschen als einer zu vermittelnden „Kultur-“, nicht „Verkehrssprache“ widmen. Dafür müsse auch das Kulturprogramm der Lektorate verstärkt werden, etwa durch vermehrte Vorträge. Ferner müßten die zukünftigen Lektoren besser als bisher in einem speziellen sechsmonatigen Vorbereitungsseminar für ihre kulturpolitische Aufgabe im Ausland geschult werden. ${ }^{106}$ Kurzum, Seyß-Inquart plädierte mit Rückendeckung des Propagandaministers für eine Aufwertung der Deutschen Akademie von einem bloßen Instrument der Sprachförderung auf allen Niveaus zu einer Zentralorganisation auswärtiger Kulturpolitik mit ausgebildetem Fachpersonal, die sich nicht an die Massen, sondern die Eliten des Auslandes wenden sollte. Goebbels zeigte sich in seinem Tagebuch denn auch zufrieden mit der guten Statur, die sein Protegé bei der Amtseinführung gemacht habe. ${ }^{107}$

Mit einem Reichsminister, der das Vertrauen Hitlers besaß, an ihrer Spitze, der Unterstützung des Propagandaministeriums und üppig bezuschußt aus dem Reichshaushalt, schien seit Anfang 1944 die Deutsche Akademie erstmals dem von ihren Gründern 20 Jahre zuvor erhobenen Anspruch nahezukommen, Zentralstelle für die deutsche auswärtige Kulturpolitik zu werden. Die Vorstellungen des neuen Präsidenten stießen in der Akademie selbst auf positive Resonanz, deren Mitarbeiter sich erhofften, unter der neuen Führung die Bevormundung in der Auslandsarbeit seitens der DWI eines Tages abstreifen zu können. So erklärte Generalsekretär Schmitz, der sich dem Propagandaministerium seit seiner Ent-

106 Beide Redemanuskripte befinden sich als Sonderdruck in: BAB R51/7.

107 Die Tagebücher von Joseph Goebbels Teil 2, Bd. 11, S. 278. 
sendung nach München offenbar zunehmend entfremdete, ${ }^{108}$ auf der Tagung der Mittelstellenleiter im Februar 1944, er habe seit der Ernennung Seyß-Inquarts den Eindruck, erstmals stehe hinter der Deutschen Akademie eine wirkliche Macht. Seyß-Inquart wolle die Deutsche Akademie so groß machen, daß ihr eines Tages die Betreuung der DWI zufallen werde. Vorerst jedoch sollten die Mittelstellen der Akademie im Ausland alle Vorfälle dokumentieren, die auf eine Einschränkung der Arbeit der Lektorate durch das Auswärtige Amt und seine Kulturinstitute schließen ließen. ${ }^{109}$

Der neue Präsident stürzte sich mit großem Eifer in seine Aufgabe, die er nicht nur als bloßen Repräsentationsposten betrachtete und die ihm anscheinend mehr Befriedigung verschaffte als die zunehmend schwierigere Herrschaft über die so gar nicht in das "Großdeutsche Reich“ integrationswilligen Niederländer. So schrieb er in einem Neujahrsgruß im Januar 1945 an seinen Vertreter Wüst in München, die Beschäftigung mit der Deutschen Akademie sei für ihn eine der schönsten und befriedigendsten Erinnerungen an das vergangene Jahr. ${ }^{110} \mathrm{Er}$ war auch nicht gewillt, sich vom Propagandaministerium gängeln zu lassen. Als im Frühjahr 1944 das Propagandaministerium Beamte nach München schicken wollte zwecks Überprüfung der Arbeit der Akademie, wies Seyß-Inquart von Den Haag aus Wüst und Schmitz an, diesen den Zugang zu den Akten zu verwehren. Er erinnerte Goebbels in einem Brief im Juni 1944 daran, daß das Propagandaministerium ihm vor Übernahme des Präsidentenamtes zugesagt habe, es werde sich nicht direkt in die Angelegenheiten der Akademie einmischen.111 „Einige Schwierigkeiten habe ich mit Seyß-Inquart bezüglich der Führung der Deutschen Akademie. Er scheint mir etwas rebellisch zu werden“, lautete denn auch eine Tagebucheintragung Goebbels' vom 22. Juni $1944 .{ }^{112}$

\section{Verstärkung der wissenschaftlichen Arbeit}

Die Gefahr, daß die Akademie vor allem durch das Desinteresse der federführenden Reichsressorts zu einem „bloßen Sprachinstitut" herabgewürdigt werde, die noch Siebert und seine Vorgänger umgetrieben hatte, schien unter dem neuen, energischen und einflußreichen Präsidenten endgültig gebannt zu sein. Bei einer Ende Januar 1944 stattfindenden Ressortbesprechung in München zwischen Seyß-Inquart, Schmitz, Heitzer sowie Vertretern des Auswärtigen Amts, des Propagandaministeriums und des RMEWV konstatierte man übereinstimmend, daß

108 So überlegte man im Propagandaministerium 1944, man könne Schmitz eventuell dadurch zu Fall bringen, daß er sich in München mit einem Professorentitel schmückte, der ihm eigentlich gar nicht zustehe. Einige Schriftstücke dazu in: BAB R55/177.

$109 \mathrm{BAB}$ R51/26, Protokoll der Tagung der Mittelstellenleiter, 11.-16. 2. 1944, ähnliche Hinweise finden sich in: BAB R21/537, Bericht über die Ressortbesprechung bei der Deutschen Akademie in München, 30.1. 1944; BAB R51/8, Aufzeichnung über die Tätigkeit der Auslandslektorate, 21. 12. 1943.

110 BAB R51/12, Schreiben Seyß-Inquart an Wüst, 13. 1. 1945.

111 BAB R55/177, Schreiben Seyß-Inquart an Goebbels, 5. 6. 1944.

112 Die Tagebücher von Joseph Goebbels Teil 2, Bd. 13, S. 512. 
die wissenschaftliche Tätigkeit der Münchener Einrichtung bisher auf Einzeluntersuchungen gerichtet und vom Zufall geleitet gewesen sei. Die bisherigen Veröffentlichungen seien zusammenhanglos und ohne innere Beziehung zu ihrer eigentlichen Aufgabe. Nunmehr werde die wissenschaftliche Abteilung großzügig ausgebaut durch Schaffung eines festen Mitarbeiterstabes. Vor allem die systematische Erforschung der deutschen Sprache und Kultur in ihren Beziehungen zum Ausland solle jetzt begonnen werden. Die Lektorate müßten stärker "wissenschaftlich unterbaut" werden und das Goethe-Institut die ausreisenden Lektoren zukünftig besser auf ihren Auslandseinsatz vorbereiten. ${ }^{113}$

Eine Initiative Seyß-Inquarts unmittelbar nach seinem Amtsantritt war die Umbenennung der Abteilungen der Deutschen Akademie in Anlehnung an das Gliederungsmuster der anderen wissenschaftlichen Akademien in eine „Klasse Forschung und Wissenschaft", welche die Sektionen der vormaligen wissenschaftlichen Abteilung umfaßte, und eine „Klasse Kulturaustausch“, welche sich aus den Abteilungen Auslandslektorate, Goethe-Institut, Länderausschüsse ${ }^{114}$ und Vortragsaustausch (mit dem Ausland) zusammensetzte. Seyß-Inquart, dabei sicherlich unterstützt, wenn nicht sogar angetrieben von Wüst, wollte die wissenschaftlichen Aktivitäten der Deutschen Akademie mit Nachdruck wiederbeleben, denn seiner Auffassung nach konnte sie sich vor der Welt nur durch eigenständige Forschungen legitimieren. Nur diese würden der gleichzeitigen Kulturwerbung der Akademie im Ausland den nötigen Nachdruck verleihen. Um den neuaufgestellten Anspruch, eben auch eine wissenschaftliche Akademie zu sein, zu untermauern, veranlaßte er vor allem die Umbenennung der früheren Abteilungen in "Klassen“. 115 Goebbels schien dieser Neuerungseifer etwas zu weit zu gehen. Schon etwas mehr als zwei Monate nach der feierlichen Amtseinführung Seyß-Inquarts notierte er in seinem Tagebuch, die Deutsche Akademie habe sich unter der Führung Seyß-Inquarts etwas zu stark auf die wissenschaftliche Forschung versteift und ihre eigentliche Aufgabe, die Verbreitung der deutschen Sprache und deutscher Kultur im Ausland, darüber vernachlässigt. ${ }^{116}$

Finanziell brachen für die wissenschaftliche Abteilung bzw. die Klasse „Forschung und Wissenschaft" im Zeichen der staatlichen Subventionierung und des starken Interesses Seyß-Inquarts an allen Aspekten der Akademiearbeit kurzfristig goldene Zeiten an. Bis 1941 hatte die Deutsche Akademie sich eher an bereits bestehenden Forschungsvorhaben beteiligt und diese im Rahmen ihrer bescheide-

113 BAB R21/537, Bericht über die Ressortbesprechung bei der Deutschen Akademie am 22. 1. 1944, Aufzeichnung vom 30.1. 1944.

114 Die Tätigkeit der Länderausschüsse ruhte seit Kriegsausbruch mehr oder weniger. Selbst in dem üppig bemessenen Etat der Deutschen Akademie für 1944 waren nur ganze 10000 RM für sie reserviert. Zudem gab es seit 1942 auch eine Doppelung dahingehend, $\mathrm{da}$ es nunmehr eine Abteilung für deutsch-balkanische Beziehungen in der Klasse „Forschung und Wissenschaft" gab, aber auch weiterhin einen zumindest formal bestehenden Süd-Ost-Ausschuß, beide im übrigen unter der Leitung des Prof. Franz Dölger. Vgl. das Organigramm der Deutschen Akademie vom Frühjahr 1944 in: BAB R2/4780.

115 Seine Motive legte Seyß-Inquart in einem Brief an Reichsinnenminister Himmler vom 28. 3. 1944 dar, in: BAB R1501/127176.

116 Die Tagebücher von Joseph Goebbels Teil 2, Bd. 12, Eintragung vom 19. 4. 1944 (S. 148). 
nen finanziellen Möglichkeiten unterstützt, nunmehr sollte sie Publikationsvorhaben nicht nur selbst initiieren, sondern durch einen eigenen Mitarbeiterstab vollständig betreuen und finanzieren. ${ }^{117}$ Die Sektionen wurden bereits Ende 1941 in kleinere Abteilungen aufgesplittet, ja es entstanden sogar noch neue: $\mathrm{Zu}$ den aus den vormaligen Sektionen hervorgegangenen, nun „Abteilungen“ genannten Untergliederungen für Volkskunde, Sprache, Schrifttum, Altertumskunde, Geschichte, bildende Kunst, Musik, Staats- und Wirtschaftskunde traten nun noch die Abteilungen für deutsch-romanische, deutsch-balkanische und deutsche Ostbeziehungen. Im Haushalt für das Jahr 1944 waren für die wissenschaftliche $\mathrm{Ab}-$ teilung $520000 \mathrm{RM}$ vorgesehen. Ihr standen jetzt 31 Planstellen zu, davon 13 wissenschaftliche Referenten. Sie verfügte damit zwar nur über einen Bruchteil des Geldes, das in jenem Jahr für die Auslandsarbeit der Abteilungen Auslandslektorate (7,23 Millionen $\mathrm{RM})$ und Goethe-Institut (720000 RM) vorgesehen war, aber auch ihr Etat hatte sich im Vergleich zu den dreißiger Jahren mehr als verzehnfacht. Ihr Budget für 1944 entsprach ungefähr dem Gesamtetat der Preußischen Akademie der Wissenschaften, der bis dahin größten und renommiertesten der wissenschaftlichen Akademien in Deutschland, die im Jahre 1944 insgesamt über 552000 RM verfügte. Der Forschungsetat der Deutschen Akademie war damit mehr als doppelt so hoch wie jener der Bayerischen Akademie der Wissenschaften, die in den letzten Kriegsjahren über etwa $200000 \mathrm{RM}$ jährlich verfügte. ${ }^{118}$

In jenen drei neuen Abteilungen, die sich mit spezifischen geographischen Großräumen befaßten, waren u.a. die Leiter der DWI auf dem Balkan und in den romanischen Ländern vertreten. ${ }^{119}$ Die Abteilung für deutsch-balkanische Beziehungen arbeitete seit ihrer Gründung an einem „Balkan-Lexikon“, einer Art Ratgeber für deutsche Diplomaten, Wissenschaftler und Wirtschaftsführer, die Abteilung für Ostbeziehungen an einem entsprechenden „Ost-Lexikon“. Alle Abteilungen sollten sich nun vor allem der Erforschung des kulturellen Einflusses Deutschlands auf das Ausland widmen. ${ }^{120}$ Diese Forschungen waren dazu gedacht, anderen Völkern die zentrale Rolle der deutschen Kultur in Europa vor Augen zu führen. Zugleich wollte man das kulturelle Sendungsbewußtsein der Deutschen selbst stärken, indem man ihnen verdeutlichte, wie sehr Deutschland in Vergangenheit und Gegenwart andere Länder kulturell beeinflußte und dadurch auch einen kulturellen Führungsanspruch des Reichs in Europa begründete, der auch die Annexion angeblich bereits seit langem kulturell weitgehend "germanisierter" Gebiete einschließen konnte. Die Abteilung für bildende Kunst

117 So der Sekretär der wissenschaftlichen Abteilung Kunze im Februar 1944, in: BAB R51/ 26, Protokoll der Mittelstellenleitertagung, 11.-16. 2. 1944.

118 Zahlen für die Deutsche Akademie in BAB R2/4780, für die Preußische Akademie in Fischer (Hrsg.), Die Preußische Akademie der Wissenschaften, S. 533. Der Etat der Bayerischen Akademie der Wissenschaften betrug für das Haushaltsjahr 1945/46197550 RM, in: BAK Z45F 5/297-3/26.

119 Für die deutsch-romanische Abteilung, die am 1. 1. 1942 ihre Arbeit aufnahm, vgl. Frank Hausmann, „Vom Strudel der Ereignisse verschlungen“, S. $434 \mathrm{f}$.

120 Hinsichtlich" der Aufgaben der neuen Abteilung für deutsche Ostbeziehungen vgl. Münchener Neueste Nachrichten vom 10. 9. 1942. 
organisierte beispielsweise im Jahr 1942/43 eine Wanderausstellung durch mehrere deutsche Großstädte, die dem Einfluß der deutschen Kunst auf Ost- und Südosteuropa gewidmet war. ${ }^{121}$

Auftrieb innerhalb der Akademie erhielt durch den „Führererlaß“ von 1941 insbesondere die Abteilung für deutsche Sprache, die während des Krieges zunächst der in München lehrende Erich Gierach leitete, und, nachdem dieser im Dezember 1943 verstarb, von dem in Leipzig lehrenden Theodor Frings übernommen wurde. Sie sollte als einzige Abteilung der Klasse „Forschung und Wissenschaft" dezidiert eigenständige Forschungen betreiben, da die Deutsche Akademie ja seit 1941 praktisch das Zentralinstitut für alle die deutsche Sprache betreffenden Fragen geworden war. Im Zentrum ihrer Forschungen stand eine großangelegte "Geschichte der deutschen Sprache“, wobei man zunächst das bereits Anfang der dreißiger Jahre begonnene althochdeutsche Wörterbuch abschließen wollte. Im Frühjahr 1944 war man bis zum Buchstaben „ $R$ “ vorgedrungen und es wurde die baldige Arbeitsaufnahme für ein frühmittelhochdeutsches Wörterbuch anvisiert. ${ }^{122}$ Ferner gab es in der Abteilung seit Anfang 1942 eine Stelle für deutsche Namensforschung, ein Handschriftenarchiv sowie eine Sammelstelle für historische Wörterbücher. Außerdem arbeitete man an der geplanten Reihe „Das deutsche Wort in fremden Sprachen“, einem sudetendeutschen Mundartenwörterbuch, Sonderwörterbüchern zu deutschen Autoren des Mittelalters und einem süddeutschen Sprachatlas. Die anderen Abteilungen hingegen sollten eher bestehende Forschungen in repräsentativen oder handbuchartigen Veröffentlichungen zusammentragen und somit der in- wie ausländischen Öffentlichkeit zugänglich machen. Das Großprojekt der Abteilung für deutsches Schrifttum unter dem in Göttingen lehrenden Hermann Pongs war eine achtbändige Geschichte der deutschen Literatur, deren erster Band 1943 erschien. ${ }^{123}$ Geplant waren ferner Werksausgaben bedeutender Schriftsteller wie Schiller, Hebbel, Mörike und Klopstock und kostengünstige „Volksausgaben“ herausragender Einzelwerke dieser Dichter. Die Abteilung deutsche Geschichte unter Karl Alexander von Müller arbeitete an der Herausgabe eines „Handbuchs der deutschen Geschichte“. Die Abteilung Musik unter Ludwig Schiedermair erforschte nunmehr den Einfluß der deutschen Musik auf das Ausland.

121 BAB R2/4780, Tätigkeitsbericht der Deutschen Akademie, Februar 1944.

122 So Frings in einem kurzen Arbeitsbericht anläßlich der Tagung der Mittelstellenleiter, in: BAB R51/26, Protokoll der Tagung der Mittelstellenleiter, 11.-16. 2. 1944. Tatsächlich wurde es erst in den Jahren 1952-1958 in Leipzig, wo Frings auch nach 1945 weiter lehrte, veröffentlicht.

123 Hermann Schneider, Heldendichtung - Geistlichendichtung - Ritterdichtung, Heidelberg 1943. 


\section{Auftrag Sprachpflege}

Der Amtsantritt Seyß-Inquarts Anfang 1944 führte schließlich dazu, daß innerhalb der Akademie das "Sprachamt“ seine Tätigkeit aufnahm. Da die Deutsche Akademie seit November 1941 u.a. mit der Pflege der deutschen Sprache in Deutschland betraut war, war dieses offiziell bereits am 30. Oktober 1941, als die Unterzeichnung des „Führererlasses“ nur noch eine Frage der Zeit war, gegründet worden. Laut Goebbels, der bei seiner Ansprache anläßlich der Amtseinführung Seyß-Inquarts auch kurz zu Fragen der Sprachpflege Stellung nahm, sollte die Akademie sowohl eine übertriebene Deutschtümelei verhindern, die danach trachtete, die Sprache von längst eingebürgerten Fremdwörtern zu reinigen, als auch eine Überschwemmung des Wortschatzes mit überflüssigen und unbrauchbaren Begriffen nichtdeutschen Ursprungs. Eine weitere Gefahr, auf welche die Akademie ihr Augenmerk richten müsse, sah Goebbels darin, daß, wie schon im Ersten Weltkrieg, die Sprache einer Flut von Abkürzungen und „Stummelwörtern" ausgesetzt sei. Diese berge in sich die Gefahr, daß die Sprache womöglich in einzelne Fachdialekte zerfalle und für die Gesamtheit des Volkes eines Tages nicht mehr verständlich sei. ${ }^{124}$

Initiativen, die Deutsche Akademie mit Aufgaben der Sprachpflege zu betrauen, hatte es schon, wie bereits erwähnt, seit ihrer Gründung gegeben. Dabei war auch ein „Sprachamt“ unter Beteiligung der Deutschen Akademie bereits im Frühjahr 1933 im Gespräch gewesen. Im Jahre 1935 war es anläßlich des 50. Geburtstags des Allgemeinen Deutschen Sprachvereins mit Unterstützung des Reichsinnenministeriums, das innerhalb der Reichsressorts für Sprachfragen zuständig war, immerhin zur Gründung eines „Sprachpflegeamtes“ in Berlin gekommen, auf das die Deutsche Akademie aber keinen Einfluß hatte. Wie schon der Name verriet, konnte es jedoch lediglich beratend, nicht regulierend tätig werden und blieb praktisch eine Geschäftsstelle des Sprachvereins, der, ebenso wie die Kulturabteilung des Reichsinnenministeriums, in den dreißiger Jahren von $\mathrm{Ru}$ dolf Buttmann geleitet wurde. Die Zeitschrift „Muttersprache“ des Sprachvereins diente folglich auch dem Sprachpflegeamt als Organ für seine Verlautbarungen. Das Sprachpflegeamt erlangte wegen der Ablehnung aus den Reihen des Amtes Rosenberg, dem das Unternehmen nicht NS-konform genug erschien, sowie der Abneigung Goebbels' aber keine dauerhafte Unterstützung des Regimes. Goebbels wandte sich am 1. Mai 1937 erstmals öffentlich und mit bedrohlichem Unterton („Worte lassen sich nicht ein- oder absetzen wie Studienräte“) gegen jede Art von Sprachpurismus, wie er vom Allgemeinen Deutschen Sprachverein betrieben wurde. Zwar stellte das Sprachpflegeamt wegen dieses Angriffes nicht, wie in der Literatur behauptet, 1937 seine Arbeit ein, sondern existierte, vom Innenministerium weiterhin bescheiden subventioniert, bis 1944 fort. ${ }^{125}$ Doch führte es in Berlin mit einem staatlichen Zuschuß von jährlich etwa 14000 RM ein ziemliches

124 BAB R51/7.

125 So Simon, Sprachpflege im Dritten Reich, S. 68 ff. und ihm folgend Flamm, Eine deutsche Sprachakademie, S. 320-326. Vom Gegenteil zeugen zwei Aktenbände im Bestand des Reichsinnenministeriums (BAB R1501/127185-127186). 
Schattendasein, gerade weil es zu sehr in der sprachpuristischen Tradition des Allgemeinen Deutschen Sprachvereins stand. Es beriet Unternehmen und Einzelpersonen in Fragen des richtigen Sprachgebrauchs, versuchte Einfluß auf die Wortwahl und Orthographie bei der Reichsgesetzgebung zu nehmen - so setzte es sich dafür ein, daß im Reichsjagdgesetz das Wort „Weidwerk“ auch tatsächlich mit „ei“ geschrieben wurde - und hob Wortneuschöpfungen von Schriftstellern, Firmen und öffentlichen Institutionen hervor, die sich durch ihre "germanischen" Wurzeln auszeichneten. 1938 lobte es beispielsweise den NS-Paradedichter Friedrich Blunck dafür, daß er die deutsche Sprache um Wörter wie „Aufbracht" für "Produktion“ und „Intwesen“ für "Charakter“ bereichert habe. Dennoch, trotz des Sprachpflegeamtes war bis 1941 in der Frage einer zentralen, staatlich geförderten Sprachnormierungsinstanz in Deutschland noch nicht viel geschehen.

Die Errichtung eines förmlichen „Sprachamtes“ innerhalb der Deutschen Akademie scheint im Herbst 1940 durch eine ursprünglich an Heß gerichtete Denkschrift des Germanisten Schmidt-Rohr angestoßen worden zu sein, welche Heß an die Deutsche Akademie überwies. ${ }^{126}$ Schmidt-Rohrs Auffassung, daß nicht die Rasse der ausschlaggebende Faktor bei der Entwicklung und Ausprägung der Sprache sei, und letztlich die Sprache entscheide, wer zu einem Volke gehöre, war einer Karriere als Germanist im Dritten Reich nicht gerade förderlich gewesen. So war ein Habilitationsversuch in München gescheitert. Er hatte sich bis Ende der dreißiger Jahre immerhin soweit der Rassedoktrin des NS-Regimes angenähert, daß er nun behauptete, die Herkunft bestimme, wer potentiell Deutscher sein könne, die Sprache aber letztlich, wer tatsächlich zum deutschen Volk zu zählen sei. ${ }^{127}$ Dennoch wurde Schmidt-Rohr in einer Denkschrift aus dem Umfeld des „Stellvertreters des Führers“ über die Lage auf dem Gebiet der Germanistik im Reich noch im März 1941 als „sehr gefährlicher Mann“ bezeichnet. Sein einflußreiches Buch „Muttersprache“ vertrete die irrige Auffassung, die Sprache und nicht die Rasse sei für die Volkszugehörigkeit ausschlaggebend.128

Schmidt-Rohr versuchte jedenfalls in der in martialischen Tönen verfaßten Denkschrift die Einrichtung eines Sprachamtes vor allem in Hinblick auf die sprachliche Auseinandersetzung mit anderen Völkern zu rechtfertigen: Den Selbstbehauptungswillen von Niederländern, Elsässern und Tschechen, so befand er, könne man durch Zerstörung ihrer Sprachen und Dialekte unterminieren, um sie sodann durch sprachpolitische Mittel zu Deutschen umzuformen. In der Deutschen Akademie wurde die Forderung nach Errichtung einer zentralen Sprachpflegeeinrichtung u.a. vom Leiter des Goethe-Instituts, Derleth, befürwortet. Allerdings sah dieser die Aufgaben eines Sprachamtes innerhalb der Aka-

126 Die Denkschrift ist abgedruckt bei Gerd Simon, Materialien über den Widerstand in der deutschen Sprachwissenschaft des Dritten Reiches. Der Fall Georg Schmidt-Rohr, in: Simon (Hrsg.), Sprachwissenschaft und politisches Engagement, S. 153-206, hier S. 166170.

127 Hutton, Linguistics in the Third Reich, S. 290 ff.; Simon, Wissenschaft und Wende 1933, passim.

128 IfZ MA 544, Schreiben des Stellvertreters des Führers an den Beauftragten des Führers für die Überwachung der gesamten weltanschaulichen Schulung und Erziehung der NSDAP, 26. 3. 1941. 
demie eher darin, Normen für die Verbreitung eines hinsichtlich der Wortwahl und Orthographie möglichst vereinheitlichten Deutsch im Ausland zu erarbeiten. Den „sprachzersetzenden“ Aufgaben im Ausland, die Schmidt-Rohr bei seinen Vorschlägen für ein Sprachamt in den Vordergrund gestellt hatte, erteilte er eine eindeutige Absage, da kein Volk sich seine Muttersprache nehmen lasse. ${ }^{129}$ Aufgegriffen und wesentlich gefördert wurde die Initiative Schmidt-Rohrs für ein Sprachamt vor allem von Gierach, der schon als Aktivist im Allgemeinen Deutschen Sprachverein um die Jahrhundertwende für eine solche Institution eingetreten war und auch Hilfestellung bei der Gründung des Sprachpflegeamts in Berlin geleistet hatte. ${ }^{130}$ Fochler-Hauke, Wüst als Präsident der wissenschaftlichen Abteilung und schließlich Siebert, die ohnehin die Sprachpflege zukünftig bei der Akademie verankern wollten, stimmten der Idee eines förmlichen Sprachamtes innerhalb der Akademie zur Jahreswende 1940/41 zu.

$\mathrm{Daß}$ das Sprachamt erst mit mehr als zweijähriger Verzögerung unter der Ägide Seyß-Inquarts aktiv wurde, lag vor allem an personellen Problemen: Der von Gierach ursprünglich vorgeschlagene Leiter, der in Erlangen lehrende Professor für Rhetorik Ewald Geißler, den Gierach mit der Aufforderung „Werden Sie Sprachpapst!“ zu ködern versuchte, lehnte nach zweijähriger Bedenkzeit die ihm angetragene Stelle schließlich ab, während Gierach selbst im Dezember 1943 verstarb. Daraufhin übernahm der promovierte Germanist und frisch ernannte Lehrbeauftragte an der Münchener Universität, Otto Basler, den Posten. Basler hatte bereits 1935 bis 1937 das Sprachpflegeamt in Berlin geleitet, bevor er, da hauptberuflich als Bibliothekar im Dienste der Wehrmacht tätig, 1937 in München Direktor der Bayerischen Armeebibliothek wurde. ${ }^{131}$ Im Haushaltsplan für 1944 waren für das Sprachamt in München drei wissenschaftliche Planstellen vorgesehen, während die Subventionen des Reichsinnenministeriums für das Sprachpflegeamt in Berlin eingestellt wurden. Daß das Sprachamt der Deutschen Akademie 1944 das Erbe des Berliner Sprachpflegeamtes antrat, wird auch daran deutlich, daß der zweite Band des zunächst vom Sprachpflegeamt betreuten "Jahrbuchs der deutschen Sprache", dessen erster Band 1941 erschienen war, 1944 unter Schirmherrschaft der Deutschen Akademie erschien.

Die Arbeitsaufnahme des Sprachamtes führte nicht zu einer Flurbereinigung in der sprachpflegerischen Landschaft des Dritten Reiches. Der Allgemeine Deutsche Sprachverein existierte weiter, obwohl $\$ 4$ des „Führererlasses“ den Präsidenten der Akademie dazu ermächtigt hatte, auf sprachpolitischem Gebiet konkurrierende, privatrechtlich verfaßte Einrichtungen aufzulösen. In München versuchte man vielmehr mit ausdrücklicher Rückendeckung von Goebbels, ${ }^{132}$ die Mitglieder des Deutschen Sprachvereins gleichsam in die Arbeit des Münchener

129 Stellungnahme Derleths vom 19.12. 1940, abgedruckt in: Simon, Materialien über den Widerstand, S. 170-176.

130 So schrieb Kunze in seinem Brief an Fochler-Hauke vom 28. 1. 1942, Gierach habe auf die Errichtung des Sprachamtes gedrängt, in: BAB R51/10134. Vgl. auch Simon, Sprachpflege im Dritten Reich, S. $73 \mathrm{ff}$.

131 Ebenda. Zu Basler vgl. Kerstin Steiger, Otto Basler, in: Internationales Germanistenlexikon, Bd. 1, S. 93-95.

132 Die Tagebücher von Joseph Goebbels Teil 2, Bd. 12, Eintragung vom 14. 4. 1944 (S. 104). 
Sprachamtes einzuspannen, „um dadurch die etwa 40000 beflissenen, um nicht zu sagen fanatischen Anhänger eines korrekten Sprechens zu gewinnen und diese andererseits vor Übertreibungen zu bewahren“, wie es in einem Brief Seyß-Inquarts an Reichsinnenminister Himmler hieß.133 Das Reichsinnenministerium hatte nichts gegen die Verschmelzung von Sprachamt und Sprachverein einzuwenden und war bereit, dieses als zukünftige Beratungsstelle der Reichsbehörden in Fragen des richtigen und verständlichen Sprachgebrauchs anzuerkennen. ${ }^{134}$ Allerdings verhinderte das Kriegsende die Realisierung der Pläne.

„Sprachzersetzend“ im Sinne der ursprünglichen Intention Schmidt-Rohrs, der im übrigen seit 1943 in der geheimen sprachpolitischen Forschungsstelle des "Ahnenerbes“ untergekommen war, wurde das Sprachamt nicht tätig, eher sprachnormierend im Sinne Derleths, für den ein genormtes und auf logischen Regeln basierendes Deutsch nicht zuletzt Voraussetzung für eine erfolgreiche Verbreitung der Sprache Goethes im Ausland war. Das Sprachamt der Deutschen Akademie befaßte sich mit der Erforschung und Dokumentation der Gegenwartssprache, also Aspekten der Rechtschreibung, des Aufkommens neuer Wörter und einmal mehr der Frage, ob Antiqua oder Fraktur die geeignete Normschrift sei. Es sollte in Abstimmung mit dem Reichserziehungs-, Propagandaund Innenministerium einheitliche Richtlinien auf dem Gebiet der Rechtschreibung und Zeichensetzung ausarbeiten. ${ }^{135}$ Es plante, sprachwissenschaftliche Untersuchungen anzuregen und Preise für besonders verdiente Forschungen auf diesem Gebiet zu vergeben. Gedacht war z.B. an Untersuchungen zur Sprache in den Großstädten, aber auch zur aktuellen Soldatensprache und zur Frage, inwieweit das Aufeinandertreffen verschiedener Bevölkerungsgruppen durch kriegsbedingte Erscheinungen wie Evakuierungen aus den von Bomben bedrohten Großstädten in ländliche Gebiete die Sprache veränderten. Aus der Sicht des Sprachamtes war der Krieg also vornehmlich ein linguistischer Großversuch. Daneben sollte das Sprachamt durch allgemeinverständliche Publikationen das Bewußtsein der Deutschen für ihre Sprache und deren Wandel schärfen. Dazu sollte vor allem das bereits erwähnte "Jahrbuch der Deutschen Sprache“ dienen. Allerdings war seine Auflage mit 700 Stück zu gering bemessen, um wirklich spracherzieherisch auf weitere Kreise der Öffentlichkeit zu wirken. Ferner arbeitete es Ende 1944/ Anfang 1945 an einem Fremdwörterbuch, einer deutschen Grammatik und einem neuen "Siebs“, also dem 1898 erstmals aufgelegten und seitdem mehrmals überarbeiteten Standardwerk der deutschen Bühnensprache, das die Maßstäbe für die richtige Aussprache des Deutschen setzte. ${ }^{136}$ Nach den Vorstellungen des Sprachamtes sollte es jetzt ein einheitlicher Ausspracheratgeber für Bühnen, Rundfunk

133 BAB R1501/127176, Schreiben von Seyß-Inquart an Himmler, 28. 3. 1944. Darauf hatten sich bei einer Sitzung des Kleinen Rates der Akademie, Auswärtiges Amt, Propagandaministerium und RMEWV geeinigt, wie aus einer Aufzeichnung des Reichserziehungsministeriums vom 13. 4. 1944 hervorgeht, in: BAB R21/537.

134 BAB R1501/127176, Stellungnahme des Reichsinnenministeriums zum Schreiben SeyßInquarts, 30.6. 1944.

135 BAB R21/537, Aufzeichnung des RMEWV, 13. 4. 1944.

136 Theodor Siebs, Deutsche Bühnensprache. Hochsprache, Auflage Köln 151930. 
und Film werden, da die neuen Medien zunehmend die für die Aussprache normende Funktion übernommen hatten, welche früher den Theaterbühnen zugekommen war. ${ }^{137}$

\section{Zwischen Sprachförderung und Propaganda}

Neben dem Ausbau der Klasse „Forschung und Wissenschaft" und der Arbeitsaufnahme des Sprachamtes wirkte sich der Amtsantritt Seyß-Inquarts auch auf die Auslandsarbeit der Akademie aus. Da Propagandaministerium und Seyß-Inquart im vorhinein übereingekommen waren, daß sich die Deutsche Akademie über den Rahmen einer bloßen Sprachförderungseinrichtung hinausentwickeln sollte, glaubte man, zukünftig ein stärkeres Augenmerk auf das zu entsendende Personal und seine Tätigkeit im Ausland richten zu müssen. Das Goethe-Institut sollte sich folglich auch zu einer Art kulturpolitischem Vorbereitungsseminar für ausreisende Lektoren entwickeln, in dem die zukünftigen Auslandskräfte nicht mehr nur wie bislang in die Methodik des Deutschunterrichts für Ausländer eingewiesen wurden. Aus diesen Überlegungen resultierte die im Haushalt für 1944 vorgesehene Verdopplung des Mitarbeiterstammes im Goethe-Institut. Es war auch beabsichtigt, dem Goethe-Institut mit dem Literaturwissenschaftler Günther Weydt, einem auslandserfahrenen Lektor, der u.a. Mittelstellenleiter in Brüssel gewesen war und nun Professor an der Universität Bonn, einen neuen Direktor zu geben, der den seit 1935 amtierenden Sprachdidaktiker Derleth ablösen sollte. ${ }^{138}$ Zugleich wünschte sich Seyß-Inquart das Goethe-Institut als eine „sprachpolitische Forschungsstelle", die striktere Richtlinien für die Auslandsarbeit der Akademie ausarbeiten sollte. Hierbei wollte man vor allem aus den Aktivitäten und Erfahrungen der anderen Nationen auf sprachpolitischem Gebiet lernen. Dazu bat man das Auswärtige Amt, der Akademie erbeutete Akten gegnerischer Kulturinstitutionen künftig zur Auswertung zur Verfügung zu stellen. Ferner waren die Auslandslektorate nun angehalten, in den neutralen Ländern ein stärkeres Augenmerk auf die Tätigkeit von Einrichtungen wie dem British Council und der Alliance Française zu richten, denen man offenbar große Durchschlagskraft zumaß. So forderte Nitschke im Februar 1944 die Mittelstellenleiter unter Hinweis auf die beabsichtigte sprachpolitische Forschungsstelle auf, sich bei der Berichterstattung nicht auf eine reine Erfassung der Sprachschüler in den einzelnen ausländischen Kulturinstituten des Gastlandes zu beschränken: „Dabei interessiert uns nicht nur das Statistische, sondern wir müssen einige Stufen tiefer dringen und sehen: Wie tun sie es? Wir sollten einen vertrauenswürdigen Ausländer in die Insti-

137 Vgl. Hüter unserer Sprache. Zur Arbeit der Deutschen Akademie, in: Das Reich, 3. 12. 1944. Siehe auch BAB R51/17, Das Deutsche Sprachamt, Denkschrift Baslers vom August 1945.

138 Weydt trat sein Amt nicht mehr vor Kriegsende an. Er wurde in den fünfziger Jahren in den Pädagogischen Beirat des neuen Goethe-Instituts berufen und 1961 in den wissenschaftlichen Beirat. Vgl. Peter Gossens, Günther Weydt, in: Internationales Germanistenlexikon, Bd. 3, S. 2022-2024. 
tute hineinschicken und uns berichten lassen."139 In Schweden, so Nitschke, sei es bereits gelungen, Englischkurse zu infiltrieren.

Daneben führte das Goethe-Institut im Kriege seine traditionelle Arbeit fort. Im Sommer 1943 waren 373 Ausländer aus 17 Staaten zu den Fortbildungskursen nach München gekommen. Die letzten überhaupt abgehaltenen Sommerkurse mußten allerdings im Jahre 1944 wegen der Luftangriffe auf München in Salzburg stattfinden. Auch die Arbeit an Unterrichtsmaterialien für den Deutschunterricht ging weiter, wobei man zunehmend Sonderwünsche des Regimes berücksichtigte. Das Autorenteam Klee/Gerken arbeitete an „Lebendiges Deutsch“, dem Nachfolgeband von „Gesprochenes Deutsch" für fortgeschrittene Sprachschüler. 1943 legte das Goethe-Institut ein spezielles Deutschlehrbuch für Volksdeutsche unter dem Titel „Deutsch lernen leicht gemacht“ vor. Ferner war eine „Deutsche Sprachfibel" für die Volksdeutschen in der Wehrmacht und die ausländischen Freiwilligen der Waffen-SS in Vorbereitung, die speziell auf das militärische Vokabular abgestellt sein sollte. Der Anhang, so informierte sein Autor die Akademiekollegen, werde „das Deutschlandlied, das Horst-Wessel-Lied, den Fahneneid, die Pflichten des deutschen Soldaten, die wichtigsten Ereignisse aus der großdeutschen Geschichte und Kultur, deutsche Städte, Flüsse, Berge, eine Übersicht über die Laute und Buchstaben und endlich die starken und unregelmäßigen Verben“" enthalten. Die Ausgabe für die Waffen-SS unterscheide sich in den ersten 18 Lektionen nur hinsichtlich der Dienstgrade und einiger Meldungen, sei aber in $\mathrm{Zu}$ sammenarbeit mit der SS um zwei Lehrstücke zu „Familie“ und „Ehre“ erweitert worden. ${ }^{140}$ In Arbeit waren ferner Anfang 1944 auch spezielle Deutschlehrbücher für ausländische Kaufleute und Mediziner.

Die anvisierte sprachpolitische Forschungsstelle war, ebenso wie die im Februar 1944 angekündigte, aber nicht mehr realisierte Errichtung eines Ausbildungsseminars für künftige Auslandsdozenten der Akademie, ein deutlicher Hinweis dafür, daß Seyß-Inquart beabsichtigte, die Akademie zu einer zentralen Forschungs- und Ausbildungsstätte auf dem Gebiet der auswärtigen Kulturpolitik auszubauen. Diese sollte der Kulturpolitischen Abteilung des Auswärtigen Amts und ihren DWI eines Tages den Rang ablaufen. Die Besprechungen zwischen Seyß-Inquart und dem Propagandaministerium vor Übernahme seines Präsidentenpostens sowie seine ersten Initiativen deuten darauf hin, daß die bisherige Auslandstätigkeit der Deutschen Akademie auf beiden Seiten als noch zu wenig zentral gesteuert und politisiert erschien, und der Auftrag der Verbreitung der deutschen Sprache nun eher als Nebensache angesehen wurde. Nitschke sprach denn auch auf der Tagung der Mittelstellenleiter im Februar 1944 ganz im Sinne des neuen Präsidenten von zu erarbeitenden Richtlinien, „die unserer Arbeit eine klare Ausrichtung und eindeutige Zielsetzung geben und sie aus dem Stadium der Improvisation in ein Stadium größter Konzentration führen sollen" ${ }^{141}$

Kritik an der Spracharbeit der Akademie war schon vorher laut geworden. Auf einer Arbeitstagung der Deutschen Akademie über „Hilfsmittel im Deutschun-

139 BAB R51/26, Protokoll der Tagung der Mittelstellenleiter, 11.-16. 2. 1944.

140 Ebenda.

141 Ebenda. 
terricht für Ausländer" in München im Mai 1942 hob Gerken beispielsweise für das Goethe-Institut hervor, daß die Gefahr bestehe, häufig zu anspruchsvolle Texte im Deutschunterricht zu verwenden. Für die Sprachkurse der Unter- und Mittelstufe würden sich, so die bisherige Erfahrung des Goethe-Instituts und der Auslandslektorate, besonders Anekdoten, Kurzgeschichten, Fabeln, Märchen und Schilderungen des Alltagslebens in gepflegter Umgangssprache eignen. Bei der Literaturlektüre in den Oberkursen hätten sich am besten die großen Novellisten des 19. Jahrhunderts bewährt. Auf Gerkens Vortrag hin entwickelte sich eine lebhafte Diskussion, inwieweit die im Unterricht verwendeten Texte zukünftig auch die unmittelbare Gegenwart des nationalsozialistischen Deutschlands reflektieren sollten. Der Vertreter des Propagandaministeriums hielt es für unerläßlich, zukünftig im Deutschunterricht nicht nur die Kunst und Literatur des NS-Regimes einzubeziehen sowie die Probleme des „neuen“ Deutschlands zu behandeln, sondern auch politisches Schrifttum von Hitler und Goebbels zu verwenden. Auch Vertreter anderer Institutionen, selbst jener des Auswärtigen Amts, fielen in diesen Chor ein und forderten, daß das nationalsozialistische Deutschland im Sprachunterricht stärker berücksichtigt werden solle. Der Ausländer habe ein Recht darauf, über Themen wie „Arbeitsdienst“, „Fallschirmjäger" (!) und den „Bauer in der Erzeugerschlacht“ mehr zu erfahren. ${ }^{142}$ Angesichts dieser Forderungen der Ministerien war es kein Wunder, daß das methodisch zwar innovative, ja wegweisende Lehrbuch "Gesprochenes Deutsch“, das auf nationalsozialistisches Gedankengut oder Bezüge zum Alltag im Dritten Reich weitgehend verzichtete, ${ }^{143}$ in Berlin nicht sonderlich populär war. ${ }^{144}$

Der Anspruch, die Auslandsarbeit der Deutschen Akademie zumindest theoretisch nicht allzu offen in den Geruch politischer Propaganda geraten zu lassen und auf die Einschätzung der kulturpolitischen Vertreter vor Ort zu vertrauen, wurde in der Akademiearbeit wie auch bei anderen kulturellen Aktivitäten des Dritten Reiches im Ausland, sofern sie unter der Aufsicht des Auswärtigen Amts standen, zumindest bis etwa 1942 beibehalten. Bis dahin wurde die Wilhelmstraße an entscheidender Stelle von Diplomaten geprägt, die wie von Twardowski und von Weizsäcker ihre berufliche Prägung hinsichtlich auswärtiger Kulturpolitik in der Weimarer Republik erhalten hatten und daher in der Tradition der Trennung zwischen langfristig wirkender „unpolitischer" Kulturpolitik und politischer, auf unmittelbare Effekte abzielender Propaganda standen. So erläuterte von Twar-

142 BAB R51/35, Bericht über die Arbeitstagung "Hilfsmittel des Deutschunterrichts für Ausländer“, 4./5. 5. 1942.

143 Die 12. Auflage von 1942 weist nur an vier Stellen Bezüge zum Dritten Reich auf: In einer der frühen Lektionen wird das „Petri heil“ eines Anglers mit einem „Sieg heil“ einer anderen Person beantwortet (S. 99), in Lektion 32 wird amerikanischen Touristen für ihre Hochzeitsreise der Besuch Münchens als „Hauptstadt der Bewegung“ und "Stadt der deutschen Kunst" empfohlen, in Lektion 34 hält ein Bauer den Reichsarbeitsdienst für eine nützliche Einrichtung, da er ihm bei der Ernte geholfen habe, und in Lektion 35 wird eine Fabrik vorgestellt, die als "Musterbetrieb“ der "Deutschen Arbeitsfront“ ausgezeichnet worden ist.

144 Vgl. auch Kapitel IV. 
dowski auf einer Tagung der Kulturreferenten der Botschaften im August 1942 in Berlin den Zuhörern:

„Unter Propaganda verstehe ich den Versuch der Beeinflussung der öffentlichen Meinung eines Landes in bezug auf eine akute politische oder wirtschaftliche oder militärische Situation. Propaganda arbeitet also auf absehbare Zeit [...] Demgegenüber heißt Kulturpolitik treiben, einen geistigen Führungsanspruch aufstellen und durchsetzen, heißt geistige Zusammenarbeit zwischen den Nationen organisieren, heißt vor allem die einflußreiche, auserwählte geistige Führerschicht in anderen Ländern dauernd geistig beeinflussen und vom deutschen Geiste abhängig zu machen. Erfolgreiche Kulturpolitik setzt also voraus: höchste kulturelle Leistung des eigenen Landes, einen weitvorausschauenden Plan für die Intensivierung der kulturellen Beziehungen zum Ausland, viel Zeit, damit die Dinge reifen können, sehr viel Geld und einen vorzüglichen Mitarbeiterstab.“

An späterer Stelle des Vortrages äußerte sich von Twardowski systemkritisch, indem er gerade die Gewaltpolitik des Dritten Reiches und die Militarisierung der politischen Kultur in Deutschland als Gründe dafür heranzog, an den aus Zeiten der Weimarer Republik überkommenen Grundsätzen der auswärtigen Kulturpolitik festzuhalten, d.h. dem Verzicht auf Zwang und politische Aufdringlichkeit bei gleichzeitiger Respektierung des Grundsatzes der Gegenseitigkeit: Der deutsche Kulturexport, so von Twardowski, leide daran, daß die Deutschen im Ausland zwar geachtet, aber nicht beliebt seien und das deutsche Lebensideal - laut von Twardowski „Disziplin, Leistung, ständige Opferbereitschaft, die Arbeit als Inbegriff des Lebens, kurz die soldatische Haltung“- übe wenig Anziehungskraft auf die Führungsschichten anderer Völker aus.

"Gegenüber der allgemein nicht sehr begeisterten Einstellung der Ausländer zur deutschen Kultur und ihren Idealen können wir nur wirken, wenn wir uns als Richtschnur strikt an folgende Prinzipien auch gegenüber den kleinsten und schwächsten und kulturärmsten Staaten halten: völlige Freiwilligkeit, also kein politischer und wirtschaftlicher $Z$ wang für irgendwelche Kulturarbeit, Gleichberechtigung und Gegenseitigkeit, also nicht Gewalt, sondern Überredung, möglichst Kulturaustausch, nicht einseitige Leistung, kurz unsere Kulturpolitik muß mit Samthandschuhen, unter strikter Schonung der großen Empfindlichkeiten gerade der kleinen Völker durchgeführt werden."

Er ermunterte auch die Kulturreferenten, Eigeninitiative zu entwickeln, da sie am besten den Geschmack des Publikums vor Ort einschätzen könnten: „Ich habe mitunter den Eindruck, daß manche von Ihnen zu schüchtern sind und Anfragen als Anweisungen sehen." ${ }^{145}$ Auf der Mittelstellenleitertagung der Deutschen Akademie im Februar 1944 erklärte der Karrierediplomat Ernst Achenbach, seit Frühjahr 1943 Referent im Auswärtigen Amt für die Belange der DWI und der Deutschen Akademie, noch ganz in diesem Geiste: „Die Kulturpolitik soll nicht politisch sein. Sie soll rein positiv und aufbauend sein. Sie hat die große Aufgabe, eine Atmosphäre der Sympathie zu schaffen, aus der bestimmte politische Forderungen leichter verstanden werden können, als es sonst der Fall ist." 146 In einer „Aufzeichnung über die Kulturpolitische Abteilung"von Twardowskis vom 10. April 1943, die wohl als eine Art Orientierung für seinen Nachfolger Franz Alfred Six und den neuen Staatssekretär Gustav Adolf Steengracht von Moyland gedacht

145 PA Bd. R60608, Vortrag von Twardowskis am 13. 8. 1942.

146 BAB R51/26, Protokoll der Tagung der Mittelstellenleiter, 11.-16. 2. 1944. 
war, hieß es denn auch: „Die Ansprüche des Propagandaministeriums auf die Deutsche Akademie haben sich bisher auf die eigentliche Auslandsarbeit noch nicht hemmend ausgewirkt." 147

Mit dem zunehmenden Einfluß des Propagandaministeriums auf Kosten des Auswärtigen Amts, der sich spätestens mit der Entsendung eines neuen Generalsekretärs im Frühjahr 1943 andeutete, wuchs jedoch die Versuchung, die Auslandsposten der Akademie stärker als bisher propagandistisch in den Dienst zu nehmen. Sie war nunmehr allein deshalb stärker, weil der Kriegsverlauf ab 1943 sich nicht mehr zu Deutschlands Gunsten entwickelte, mithin also nicht mehr die Waffenerfolge der Wehrmacht für sich sprachen, während sich zugleich in den besetzten Ländern der Widerstand formierte, und man daher in Berlin glaubte, mehr denn je auf andere Kanäle der Beeinflussung des Auslands angewiesen zu sein. Offenbar gab es schon im Mai 1943 eine Weisung des Propagandaministeriums (oder des neuen, vom Propagandaministerium entsandten Generalsekretärs Schmitz), daß die Auslandsvertreter der Deutschen Akademie in ihrer Tätigkeit zukünftig einer stärkeren Kontrolle unterworfen werden sollten. ${ }^{148}$ Auch das Auswärtige Amt hatte schließlich nichts mehr dagegen einzuwenden, leitete doch die Kulturpolitische Abteilung seit Anfang 1943 der Seiteneinsteiger in den diplomatischen Dienst und aktivistische SS-Führer Six, der im Propagandaministerium als durchaus kooperativ angesehen wurde. ${ }^{149}$ Six selbst gab im Mai 1944 auf einer Tagung der Kulturreferenten der Botschaften in Paris die Anweisung, die Lektorate sollten zukünftig mehr in die "Informationsarbeit" eingezogen werden, damit sie aus dem Rahmen reiner Sprachschulen herauswuchsen. Dazu sollten sie künftig die aktuellen Tagesparolen der sogenannten Mund- und Flüsterpropaganda erhalten. ${ }^{150}$ In einem Rundbrief an die bereits zur Wehrmacht eingezogenen Lektoren vom Mai 1944 hieß es denn auch:

„Die Propagandastaffeln der Wehrmacht in den besetzten Gebieten unterstützen die Lektorate in tatkräftiger Weise und versorgen sie mit Film-, Bücher- und Ausstellungsmaterial. Besonders glücklich ist in den besetzten Gebieten die Einrichtung von ,Deutschen Abenden', in denen Hörer des Gastlandes mit aufgeschlossenen Vertretern der Wehrmacht zusammentreffen zu Konversation und Gesellschaftsspielen. So bereichert der Hörer nicht nur seine Sprachkenntnisse, er lernt gleichzeitig auch den deutschen Menschen im Waffenrock kennen, womit für das gegenseitige Verständnis im zukünftigen Europa ungemein viel gewonnen ist." 151

Thierfelder und Zwiedineck-Südenhorst kamen in ihrer Evaluation der Auslandsarbeit der Akademie im Sommer 1945, als sie kommissarisch die Leitung der Aka-

147 PA Bd. R60804.

148 So bewertete Ziegler die Mittelstellenleitertagung der Deutschen Akademie vom Februar 1944 nicht zuletzt deshalb als Erfolg, weil die Anweisungen vom Mai 1943, die Auslandsvertreter der Akademie sich nicht mehr selbst zu überlassen, Wirkung gezeigt hätten. BAB R55/177, Bericht Zieglers an Goebbels über die Mittelstellenleitertagung vom 11.16. 2. 1944 in München.

149 BAB R55/177, Aufzeichnung Zieglers für Goebbels, 7. 1. 1944.

150 BAB R51/533, Rundschreiben des Deutschen Instituts Paris an die Provinzlektorate, 24. 5. 1944.

151 BAB R51/24, „Die Runde“, 3. Rundbrief Mai 1944. 
demie übernahmen, denn auch zu dem Schluß: „Im Großen und Ganzen aber waren 1944 die Lektorate zweifellos wichtige Stützpunkte der Parteiideologie im Ausland geworden. "Sie hätten Propaganda in "gröberer oder feinerer Form" betrieben, auch wenn viele Lektoren unter diesem Auftrag geradezu gelitten hätten, der für sie im Widerspruch zur selbstgestellten Aufgabe der kulturellen Verständigungsarbeit gestanden habe. ${ }^{152}$

Allerdings sollte man das Jahr 1943 nicht als Zäsur überbewerten, als eine Art Scheidelinie, in der die Auslandsarbeit der Deutschen Akademie unter dem „unheilvollen" Einfluß des Propagandaministeriums und dem parallelen Wechsel an der Spitze der Kulturpolitischen Abteilung des Auswärtigen Amts endgültig von „unpolitischer" Sprachwerbung in eine auf die tagespolitischen Erfordernisse abstellende propagandistische Betätigung umkippte. Ansätze hierzu gab es ja, wie gezeigt wurde, schon im Jahre 1940, als die Lektorate auf dem Balkan Propagandaschriften verbreiteten. Die Interpretation einer weitgehend „unpolitischen Kulturarbeit" selbst im Kriege machten sich jene Karrierediplomaten des Auswärtigen Amts zu eigen, die auch nach 1945 wieder im neuen Amt tätig wurden, allen voran von Twardowski in seiner stark autobiographisch geprägten und entsprechend unkritischen, 1970 erschienenen Schrift „Anfänge deutscher Kulturpolitik zum Ausland“. Ein weiteres Beispiel für die Behauptung, daß die Kulturabteilung bis gegen Ende des Krieges im wesentlichen „sauber" geblieben sei, ist eine Denkschrift vom Frühjahr 1950 des vormaligen Mitarbeiters im Referat „W“(Wissenschaft) der Kulturpolitischen Abteilung, Paul Roth. Sie sollte der wiedererstehenden Kulturabteilung des neuen Amts durch Verweis auf eine angeblich unbefleckte Tradition offenbar den Rücken stärken. So lobte Roth, der bis 1945 auf seinem Referat ausgeharrt hatte, die alte Kulturabteilung, „die übrigens, wie im einzelnen gelegentlich nachgewiesen wird, sowohl ein Eindringen nationalsozialistischen Geistes wie einen Mißbrauch im Sinne der NS-Tendenzen von sich weisen konnte“. Selbst ab 1943, als unter Six Kultur- und Informationsabteilung verschmolzen worden waren, sei es der Partei nicht gelungen, „die Tätigkeit der wirklich kulturellen Referate zu demoralisieren oder zu desorganisieren“. Von Twardowski bezeichnete denn auch in einigen ergänzenden Anmerkungen einige Monate später die Aufzeichnung Roths als "ganz vorzüglich“.153

Das Urteil darüber, inwieweit die Lektorate der Deutschen Akademie zu Zellen expliziter NS-Propaganda im Ausland wurden und wann dies geschah, kann nicht eindeutig gefällt werden: Auf der einen Seite blieb der Zugriff der NS-Propaganda auf die Deutschkurse im Ausland allein schon dadurch begrenzt, daß mangelnde Sprachkenntnisse der Teilnehmer eine politische Vereinnahmung erschwerten und umgekehrt ein politischer Unterricht dem Hauptziel, der effektiven Vermittlung deutscher Sprachkenntnisse im Wege stand, wie es u.a. die Diskussion um das Lehrbuch "Gesprochenes Deutsch" zeigte. Allein deshalb schon wollten das Propagandaministerium und Seyß-Inquart die Tätigkeit ab 1944 nach Möglichkeit auf den gehobenen Sprachunterricht verlagern. Ein Studium der Tätigkeitsberichte

152 BAB R51/8, Die politische Tätigkeit der Deutschen Akademie, Denkschrift Thierfelders und Zwiedineck-Südenhorsts vom 21. 8. 1945.

153 Beide Dokumente befinden sich in: PA B90/1. 
der Auslandslektorate im besetzten Frankreich zeigt z.B., daß der Grad der politischen Indoktrination, dem die Hörer in den Sprachkursen ausgesetzt waren, bis Sommer 1944 viel mehr vom Temperament und der politischen Gesinnung des einzelnen Dozenten als von Vorgaben aus der Zentrale abhing. ${ }^{154}$ Es gab bis zum Schluß offenbar keine festen Lehrpläne oder Literaturlisten, um den Unterricht in den Lektoraten einheitlich zu gestalten, auch wenn dies spätestens unter der Ägide von Seyß-Inquart angestrebt wurde. Außer der Benutzung des Lehrbuches von Klee/Gerken, so der 1943/44 in Paris tätige Lektor Arthur Henkel, "gab es keine weiteren Direktiven, auch keine Weichenstellungen etwa propagandistischer Art. In der Gestaltung des Unterrichts war ich (jedenfalls) frei, auch in der Einbeziehung von Musik (Singen) und von Texten aus der deutschen Literaturgeschichte, die in der Oberstufe der Kurse zu lesen waren." 155

Auf der anderen Seite zeugte das Vortragsprogramm in den Lektoraten schon vor dem Personalwechsel an der Spitze der Kulturpolitischen Abteilung, dem wachsenden Einfluß des Propagandaministeriums in München und schließlich der Ernennung Seyß-Inquarts von einer deutlichen Vereinnahmung der Auslandsarbeit der Akademie für die Kriegspolitik des Dritten Reiches. Da die DWI und die Auslandsmissionen den in den Lektoraten auftretenden Referenten zustimmen mußten, war es ein Programm, das der vollen Unterstützung des Auswärtigen Amts bedurfte. Es zeigte letztlich, daß in Zeiten des Krieges die Unterscheidung zwischen „Propaganda“ und „unpolitischer" Kulturpolitik eine künstliche war, eine Einsicht, der man sich ja auch im British Council schon bei Kriegsbeginn nicht verschlossen hatte. Dabei mag das Vortragsprogramm in den Lektoraten den Organisatoren nicht einmal unbedingt als „Propaganda“ vorgekommen sein, sondern schlicht als ein Versuch, dem Ausland ein Abbild Deutschlands und seiner Interessen im Kriege zu vermitteln, zu dem man sich allein schon aus Loyalität zum im Kriege befindlichen Vaterland verpflichtet fühlte, selbst wenn man womöglich nicht alle Aspekte der Politik des NS-Regimes befürwortete. Harmlose Themen wie "Der Rhein und seine Nebentäler", "Die Musikerfamilie Bach", „Humor im Alpenvorland“, „Einführung in das Werk Hölderlins“, „Hans Holbein“, „Robert Koch“, „Das Pergamonmuseum in Berlin“ und „Italien im Erlebnis großer Deutscher" fanden sich ebenso im Programm wie Vorträge mit Kriegsbezug wie "Was ein Arzt in Rußland sah", „Die Leistungen der deutschen Wissenschaften im Kriege“, „Deutschlands Kampf im Osten“, „Für Europa kämpft Deutschland gegen England“, „Expansionsbestrebungen der amerikanischen Außenpolitik seit Roosevelt" oder lediglich wissenschaftlich kaschierte, da scheinbar historisch fundierte Rechtfertigungen für die Aggressionspolitik des Reiches, von denen Vorträge über „Deutschlands geschichtliche Stellung in Europa“ und „Der geistige Kampf um den Rhein" zeugten.156 Auch Thierfelder, der 1945 mit der Kriegsvergangenheit der Deutschen Akademie hart ins Gericht ging und sie des Verrats an ihren ursprünglichen Idealen bezichtigte, hatte sich im übrigen nach

154 Michels, Das Deutsche Institut in Paris, S. 213.

155 Brief Henkels vom 8. 3. 1991 an den Autor.

156 BAB R51/576, Bericht über die Vortragsveranstaltungen der Deutschen Akademie 1942/ 43, Aufzeichnung vom 10. 7. 1944. 
Kriegsausbruch diesem patriotischen Reflex bzw. der zumindest partiellen Identifizierung mit den Kriegszielen des Dritten Reiches nicht verschlossen und sein Fachwissen in den Dienst der publizistischen Rechtfertigung der Kriegspolitik des Dritten Reiches gestellt: Er verfaßte 1940 für die der Informationsabteilung des Auswärtigen Amts unterstehende „Deutsche Informationsstelle" zwei gegen Großbritannien gerichtete Propagandaschriften. ${ }^{157}$

Eine direkte Einbeziehung in die politisch-militärische Arbeit blieb den Auslandslektoraten hingegen bis zuletzt erspart. Die im Kleinen Rat versammelten Vertreter der Deutschen Akademie und der zuständigen Ministerien (Auswärtiges Amt, Propagandaministerium und RMEWV) kamen bei einem Treffen Mitte Februar 1944 überein, das man auch künftig davon absehen solle, die Auslandslektorate für die politische Berichterstattung heranzuziehen oder ihnen Sonderaufträge der Wehrmacht und SS aufzubürden, um nicht die Auslandsarbeit der Deutschen Akademie von vornherein zu diskreditieren und damit unwirksam zu machen. ${ }^{158}$ Sowohl Wehrmacht wie auch der Sicherheitsdienst der SS hatten zuvor verschiedentlich Interesse an der Einbeziehung der Auslandslektorate in ihre Arbeit geäuBert. 159

\section{Kulturpolitik im Schatten der sich abzeichnenden Niederlage}

Die ehrgeizigen Pläne Seyß-Inquarts für die Akademie ließen sich wegen des Kriegsverlaufes nicht mehr realisieren. Weder nahm das Ausbildungsseminar für zukünftige Lektoren seine Arbeit auf, noch die „sprachpolitische Forschungsstelle“. Es gelang auch nicht, in dem verbleibenden Jahr die DWI unter die Kontrolle der Deutschen Akademie zu bringen. Ebensowenig brachte die Klasse „Forschung und Wissenschaft" eines der wissenschaftlichen Großprojekte zu Ende. Allerdings wurden ihre Mitarbeiter - im Januar 1945 arbeiteten dort noch zehn Wissenschaftler - seit Herbst 1944 von Seyß-Inquart und Wüst gedrängt, die Öffentlichkeit durch Rundfunkbeiträge über ihre Forschungen auf die Arbeit der Akademie aufmerksam zu machen.

157 Franz Thierfelder, Das Freiheitsringen der Inder, Berlin 1940 sowie ders., Englischer Kulturimperialismus. Der British Council als Werkzeug der geistigen Einkreisung Deutschlands, Berlin 1940. Beide Schriften erschienen in der Reihe „Das Britische Reich in der Weltpolitik“, zu der auch Publikationen mit Titeln wie „Die soziale Rückständigkeit Großbritanniens“, „Das perverse England“, „England, Hinterland des Judentums“, "England als Wucherbankier" gehörten.

158 BAB R55/177, Bericht Zieglers an Goebbels über die Mittelstellenleitertagung in München und eine Sitzung des Kleinen Rates, Februar 1944.

159 Schon im April 1939 hatte die Abwehr Interesse an der Deutschen Akademie gezeigt und diese zwecks Einbeziehung in ihre Auslandsaufklärungsarbeit kontaktiert. Die Abwehr war aber vom Auswärtigen Amt gebremst worden. Vgl. Schlicker, Die Deutsche Akademie, S. 62. BAB R51/10149, Aktennotiz Nitschkes über eine Besprechung mit einem Vertreter des SD, 22. 9. 1943; zu Kontaktversuchen des SD zu den Lektoraten im besetzten Frankreich siehe Michels, Das Deutsche Institut, S. 195. 
Immerhin gelang es aber der Akademie, bis Sommer 1944 die Zahl der Lektoren in etwa auf dem Niveau von 1942, als das Dritte Reich im Zenit seiner militärischen Macht stand, zu halten, wenn auch um den Preis einer immer größeren personellen Fluktuation. Die durch den Vormarsch der Alliierten in Italien bedingte Schließung von Lektoraten im Süden der Halbinsel wurde beispielsweise durch Eröffnung neuer Lektorate im Norden des Landes ausgeglichen. Ende 1943 unterstanden der Abteilung Auslandslektorate 105 Lektorate mit 180 Lektoren sowie 170 Zweigstellen mit 560 Hilfslehrkräften und 104 in den Lektoraten tätigen Bürokräften. Die Zahl der Sprachkursteilnehmer war allerdings in beinahe allen Ländern seit Anfang 1943 im Sinken begriffen trotz des unverminderten Angebotes, wobei die größten Rückschläge in Frankreich (von etwa 15000 Hörern im Herbst 1942 auf etwa 10000 im Herbst 1943), Belgien (von 2600 auf 1700), Bulgarien (von etwa 3300 auf 2200), Dänemark (von 277 auf 132), Serbien (von 2570 auf 1750) und der Slowakei (von 2740 auf 2193) zu verzeichnen waren. ${ }^{160} \mathrm{Die} \mathrm{Ge}-$ samtbilanz der Sprachkursteilnehmer - 64000 im Herbst 1942, etwa 60000 im Herbst 1943 - fiel hauptsächlich deshalb noch relativ gut aus, weil man allein 1943 in Europa 45 neue Zweigstellen eingerichtet hatte.

Im besetzten Frankreich und Griechenland beispielsweise wurden die Sprachkursbesucher mancherorts nunmehr von ihren Landsleuten als „kulturelle Kollaborateure" gebrandmarkt. Vor allem in den Lektoraten kleinerer Orte, die weniger Anonymität boten, fiel die Zahl der Hörer. Der 1943/44 einsetzende Versuch, die Lektorate stärker in die direkte Propaganda für die deutschen Kriegsanstrengungen einzubeziehen und dabei enger mit der Wehrmacht zu kooperieren, dürfte bei den Adressaten insbesondere in den besetzten Ländern die Hemmungen, sich für Sprachkurse einzuschreiben, noch verstärkt haben. Dennoch wies die Spracharbeit der Deutschen Akademie selbst Ende 1943 eine im Vergleich zur Nachkriegszeit erstaunliche Bilanz auf: Im Herbst 1943 hatte beispielsweise das Lektorat Paris immerhin noch etwa 5000 eingeschriebene Hörer, während die Sprachkurse des Pariser Goethe-Instituts, das erst 1965 seine Arbeit in vollem Umfang aufnahm, in der zweiten Hälfte der sechziger Jahre im Schnitt lediglich 2000 bis 3000 Hörer verzeichneten. ${ }^{161}$ Dies ist sicherlich, trotz aller Probleme der Vergleichbarkeit der Zahlen, ein deutliches Anzeichen für den stetigen Bedeutungsverlust der deutschen Sprache in Europa im 20. Jahrhundert, ungeachtet der jeweiligen politischen Großwetterlage.

Man ließ sich aber weder in Berlin noch München durch die Niederlagen an allen Fronten seit 1943 und dem damit einhergehenden Hörerschwund entmutigen, im Gegenteil: Eine Aufzeichnung des Auswärtigen Amts vom Januar 1944 sah die erstmalige Errichtung von zwei oder drei Lektoraten in Albanien und einer gleichen Anzahl im Baltikum („Ostland“) und den Niederlanden vor. In Belgien, Finnland, Rumänien, Serbien, Spanien sollte jeweils ein Lektorat neu eröffnet

160 BAB R51/476, Vergleichszahlen der Kursteilnehmer 1942/43.

161 Zahlen in Michels, Das Deutsche Institut in Paris, S. 208 sowie in den Jahrbüchern des Goethe-Instituts 1965-1970, München 1966-1971. 
werden, in Ungarn zwei, in Schweden drei, in Frankreich sogar sechs. ${ }^{162}$ Die Akademie arbeite, so Nitschke einen Monat später gegenüber seinen Kollegen, derzeit an einer vertraulichen Denkschrift, welche von von Ribbentrop, Goebbels und Seyß-Inquart unterschrieben werden solle, um 50 bis 60 erfahrene Lektoren aus dem Heeresdienst wieder frei zu bekommen. ${ }^{163}$ Eine Aufstellung vom 4. August 1944 zeigt zwar, daß diese Pläne nicht mehr realisiert wurden, verzeichnet aber immer noch 184 Lektoren an 97 Orten in zwanzig Ländern, die sich wie folgt verteilten: 46 Lektoren waren in Frankreich tätig, jeweils 14 Lektoren in Italien bzw. Belgien, 13 in Rumänien, jeweils zwölf in Bulgarien, der Slowakei, Spanien und Ungarn, neun in Kroatien, sieben in Schweden, jeweils sechs in Portugal bzw. Griechenland, jeweils vier in Dänemark, Serbien und Finnland. Drei arbeiteten in China, jeweils zwei in Argentinien bzw. Norwegen. Schließlich gab es noch einen Lektor in Mandschuko und einen Mittelstellenleiter in Den Haag. ${ }^{164}$

Diese unverminderte Präsenz der Akademie im Ausland trotz der Rückschläge des Reiches seit Herbst 1942 an allen Fronten bestand nicht zuletzt deshalb fort, weil das Auswärtige Amt im Zeichen der sich häufenden Niederlagen erklärte, daß Kulturpolitik im „totalen Krieg“ im Ausland als ein Ausdruck für die ungeschmälerte Siegeszuversicht des Reiches gewertet würde. ${ }^{165}$ Dies war eine Behauptung, die nicht zuletzt dazu diente, die Tätigkeit der im Kriege erheblich aufgeblähten Kulturpolitischen Abteilung zu rechtfertigen, die im Sommer 1944 insgesamt 197 Beamte des höheren und gehobenen Dienstes sowie sogenannte wissenschaftliche Hilfsarbeiter umfaßte, also etwa fünfmal so viele Mitarbeiter wie zehn Jahre zuvor. ${ }^{166}$ Diese Auffassung wurde naturgemäß von der Deutschen Akademie geteilt, deren Mitarbeiter ein ureigenes Interesse daran hatten, ungeachtet der Situation an den Fronten weiter für die deutsche Sprache zu werben. Die Wehrmacht oder - im Falle der Lektorinnen - ein Einsatz in der Kriegswirtschaft war im Vergleich zu ihrer Lehrtätigkeit nicht gerade eine verlockende Alternative. So verkündete Nitschke auf der Tagung der Mittelstellenleiter im Februar 1944: „Auch im fünften Kriegsjahr hat Sprachwerbung entgegen der Absicht militärischer Stellen einen Sinn: Der Lektor kann durch sein bloßes Dasein und seine Haltung aller Gerüchtemacherei den Boden entziehen und den Ausländern eine Vorstellung vom deutschen Behauptungs- und Siegeswillen geben." 167

162 PA Bd. R63950a, Überblick über die Lektoratsarbeit der Deutschen Akademie im Ausland und Pläne für 1944, Januar 1944.

163 BAB R51/26, Protokoll der Tagung der Mittelstellenleiter, 11.-16. 2. 1944.

164 PA Bd. R64287.

165 Michels, Das Deutsche Institut in Paris, S. $175 \mathrm{ff}$.

166 Die Zahl für Mitte 1944 findet sich bei Hachtmeister, Der Gegnerforscher, S. 268. Für 1934 gibt Twardowski, Anfänge der deutschen Kulturpolitik zum Ausland, S. 37 f., die Zahl der Mitarbeiter der Kulturabteilung des Auswärtigen Amts mit 12 Beamten des höheren Dienstes, 22 Beamten des gehobenen Dienstes und zwei wissenschaftlichen Hilfsarbeitern an. Die Mitarbeiterzahl für 1944 ist allerdings u. a. so extrem hoch, da im Frühjahr 1943 die bei Kriegsausbruch gänzlich neu geschaffene „Informationsabteilung“ nach dem Sturz ihres Leiters, Unterstaatssekretär Martin Luther, der Kulturabteilung unter dem neuen Leiter Six einverleibt worden war.

167 BAB R51/26, Protokoll der Tagung der Mittelstellenleiter, 11.-16. 2. 1944. 
Mit dem Vormarsch der Alliierten in Italien und der Räumung Frankreichs, Rumäniens, Bulgariens, Albaniens, Griechenlands und Teilen Jugoslawiens durch die Wehrmacht im Sommer und Herbst 1944 mußten allerdings just jene Länder aufgegeben werden, in denen die Akademie sich am stärksten engagiert hatte. Zur Unterbringung der aus dem Ausland evakuierten Lektoren und ihrer Familien errichtete die Akademie daher im Juni 1944 in Untergrainau bei Garmisch-Partenkirchen ein „Rückwandererheim“, in dem die Evakuierten vorübergehend Unterkunft finden sollten. Ursprünglich nur als Notbehelf gedacht, wohnte ein Teil der Lektoren mit ihren Familien jedoch noch 1946 in diesem Heim. Im Spätsommer 1944 wurde die Klasse „Kulturaustausch“ unter Schmitz wegen der zunehmenden Luftangriffe auf München in die Nähe von Salzburg evakuiert, wo sie bis Mai 1945 blieb. Die Klasse „Forschung und Wissenschaft“ unter Vizepräsident Wüst und die Zentralverwaltung unter Heitzer hingegen arbeiteten bis Kriegsende im Maximilianeum weiter.

Selbst die Räumung von zuvor unter deutscher Kontrolle stehenden Ländern bedeutete nicht, daß Kultureinrichtungen, die in diesen Ländern tätig gewesen waren, nun gänzlich aufgelöst wurden. Denn die Kulturpolitische Abteilung des Auswärtigen Amts versuchte trotz des Rückzugs an allen Fronten und dem seit Sommer 1944 rasch schrumpfenden deutschen Machtbereich relativ erfolgreich, ihre Einrichtungen, d.h. vor allem die DWI, unter dem Hinweis zu erhalten, gerade kulturpolitische Einrichtungen seien dazu geeignet, „vorübergehende“ Phasen machtpolitischer Schwäche einer Nation aufzufangen. Dies war eine Reaktion auf eine Forderung des Erzrivalen Goebbels, der seit 25. Juli 1944 „Reichsbevollmächtigter für den totalen Kriegseinsatz" war. Er nutzte seinen neuen Posten nicht zuletzt zu dem Versuch, das Auswärtige Amt endgültig aus dem Feld der propagandistischen Beeinflussung des Auslandes herauszudrängen, indem er letztlich vergeblich - die Auflösung der Kultur-, Rundfunk- und Presseabteilung der Wilhelmstraße forderte. Zwar sollten auf Weisung des Reichsaußenministers alle auslandskulturpolitischen Einrichtungen nach entbehrlichem Personal "schärfstens durchkämmt" werden, die Einrichtungen an sich jedoch erhalten bleiben. ${ }^{168}$ Die evakuierten Institute arbeiteten in verringertem Umfang im Reich selbst weiter und betreuten dabei u.a. die geflohenen Kollaborateure aus den besetzten oder verbündeten Ländern. 169

Ende August 1944 vereinbarten Auswärtiges Amt, Propagandaministerium und Seyß-Inquart in einer Besprechung in Berlin einen ersten Personalabbau bei der Deutschen Akademie, um Soldaten für die Front freizumachen. Zunächst sollten 45 zurückgekehrte Auslandslektoren und neun Mitarbeiter der Geschäftsstelle zur Wehrmacht eingezogen werden. ${ }^{170}$ An ein Ende der Auslands- wie Forschungsarbeit der Akademie dachten jedoch weder Propagandaministerium noch Auswärtiges Amt. So hieß es Mitte Oktober 1944 in einem Rundbrief der Abtei-

168 PA Bd. 63950a, Aufzeichnung der Kulturpolitischen Abteilung betr. den Personalabbau in der Deutschen Akademie, 26. 8. 1944.

169 Michels, Die deutschen Kulturinstitute im besetzten Europa, S. $31 \mathrm{f}$.

170 PA Bd. 63950a, Aufzeichnung der Kulturpolitischen Abteilung betr. den Personalabbau in der Deutschen Akademie, 26. 8. 1944. 
lung Auslandslektorate an die bereits zur Wehrmacht eingezogenen Lektoren: „Die Weiterarbeit der Deutschen Akademie - wenn auch in eingeschränktem Umfang - ist von höchster Stelle nicht nur gestattet, sondern ausdrücklich angeordnet worden." ${ }^{171}$ Man hoffte zudem, den kriegsbedingt immer enger werdenden geographischen Aktionsrahmen der Auslandsarbeit durch vermehrte Sprachwerbung über den Rundfunk auszugleichen. ${ }^{172}$

Wie im Falle der DWI wurde die Arbeit einiger Lektorate aus den nun nicht mehr im deutschen Machtbereich liegenden Ländern seit Herbst 1944 in begrenztem Maße im Reich weitergeführt, eine Idee, die zuerst im Zusammenhang mit der Räumung Frankreichs entstanden war. Die insgesamt sieben "Inlandslektorate“ waren auserkoren, den mit der abziehenden Wehrmacht aus ihren Heimatländern geflohenen Kollaborateuren und ihren Familienangehörigen in erster Linie politische Schulungen zu erteilen und in zweiter Line auch Deutsch zu vermitteln. Denn Seyß-Inquart erläuterte auf einer Sitzung des Kleinen Rates in Berlin Ende November 1944, „daß die Akademie es sich zur Aufgabe machen wolle, bei den Vertretern der Intelligenz-Schicht der Nachbarländer, die z.T. durchaus nicht ohne weiteres als Kenner oder gar Freunde deutschen Gedankengutes gelten dürften, in einer ihrem Bildungsstand angemessenen Form Einfluß auf ihre Denkart zu gewinnen. In einem gewissen Umfang soll auch guter Sprachunterricht durch die einzurichtenden Stellen angeboten werden. " ${ }^{173}$ Dem Zweckoptimismus einer NS-Propaganda entsprechend, der es gelang, jeder Niederlage noch eine positive Seite abzugewinnen, hieß es in einem Artikel in der Zeitschrift „Das Reich" vom 3. Dezember 1944 über die Arbeit der Deutschen Akademie: „Wenn jetzt durch den Gang der militärischen Ereignisse ein Teil dieser Betätigungsfelder aufgegeben werden mußte, so fand sich die Deutsche Akademie damit nicht in Form eines passiven Verzichts ab. Ist doch ein Teil gerade der für uns wichtigsten und wertvollsten Ausländer jetzt nach Deutschland gekommen, um die Zusammenarbeit mit uns fortzusetzen. Ihnen gilt die verstärkte Betreuungsarbeit." Weiter hieß es, dieser kleine, aber anspruchsvolle Kreis von Hörern bewirke eine beträchtliche Niveauerhöhung der Arbeit, die sich nicht auf bloße Sprachvermittlung beschränke. Kurse wurden schließlich in Halle und Dresden für Ungarn, in Heidelberg und Sigmaringen für Franzosen, in Kitzbühl und Langendorf für Serben und in Zürs für Italiener eingerichtet. Allerdings berichteten die Inlandslektorate überwiegend vom Desinteresse ihrer Schüler, mangelndem Verständnis der deutschen Bevölkerung und fehlender Kooperationsbereitschaft der örtlichen Behörden, ${ }^{174}$ die am Sinn dieser „vorübergehend“ im Reich selbst stattfindenden auswärtigen Kulturpolitik zu Recht zweifelten.

In den noch nicht befreiten oder neutralen Ländern ging die Sprachwerbung und Propagandaarbeit buchstäblich bis zur Kapitulation des Reiches weiter. Eine Aufstellung der Abteilung Auslandslektorate vom 15. März 1945 wies immer noch einen Lektor in Mandschuko, jeweils zwei Lektoren in Argentinien, China,

171 BAB R51/24, 4. Rundbrief „Die Runde“, 15. 10. 1944.

172 Hüter der Sprache. Zur Arbeit der Deutschen Akademie, in: Das Reich, 3. 12. 1944.

173 BAB R21537, Vermerk über die Sitzung des Kleinen Rates in Berlin, 27. 11. 1944.

174 Einige Details hierzu in: BAB R51/21 und R51/68. 
Norwegen, der Slowakei und Ungarn, drei Lektoren in Dänemark, vier in Kroatien, fünf in Portugal, sieben in Schweden und neun in Spanien auf. In Italien waren im März 1945 sogar 15 Lektoren tätig,, ${ }^{175}$ die durch ihre Spracharbeit von der unverminderten „Siegeszuversicht“ des Reiches zu zeugen hatten. Dort arbeitete also sogar eine Kraft mehr als im Sommer 1944, obwohl inzwischen der deutsche Machtbereich auf der Halbinsel weiter zusammengeschmolzen war. Für Oberitalien forderte Generalsekretär Schmitz im übrigen Anfang März 1945 noch dringend neue Lehrkräfte. ${ }^{176}$ Allerdings hatte er einige Monate zuvor bereits angeordnet, daß die Klasse „Kulturaustausch“ eine Sammlung von positiven ausländischen Berichten über die Arbeit der Akademie anlegen solle ${ }^{177}$ - vermutlich als eine Art Rückversicherung für den Fall, daß der „Endsieg“ doch nicht den deutschen Waffen beschieden sein sollte. Das Lektorat im spanischen Cartagena ignorierte schließlich sogar die Kapitulation des Reiches und die Auflösung der Akademie und unterrichtete noch einige Jahre weiter. Sein Leiter, Kurt Graf von Posadowsky, wechselte dann 1953 fast nahtlos über in die erste Auslandsdozentur des wiedergegründeten Goethe-Instituts in Athen.

75 BAB R51/101160, Verzeichnis der Mittelstellenleiter, Lektoratsleiter und Lektoren, Stand 15. 3. 1945.

176 PA Bd. R64302, Schreiben Schmitz' an das Auswärtige Amt, 7. 3. 1945.

177 BAB R51/12. 